\title{
On the Forecast Sensitivity of MCS Cold Pools and Related Features to Horizontal Grid Spacing in Convection-Allowing WRF Simulations
}

\author{
BRIAN J. SQUITIERI AND WiLliam A. GALlus JR. \\ Department of Geological and Atmospheric Sciences, Iowa State University, Ames, Iowa
}

(Manuscript received 28 January 2019, in final form 15 October 2019)

\begin{abstract}
While the implementation of convection-allowing models has improved the representation of convective features, a consensus is lacking regarding what horizontal grid spacing most appropriately resolves convective structures, is computationally feasible, and provides the most useful output to forecasters. The present study evaluates 14 simulated MCSs with 3-, 1- and 0.333-km horizontal grid spacing in order to understand sensitivity in simulated MCS forward propagation speeds and cold pool behavior with decreased grid spacing. MCS cold pools were found to be significantly larger in runs using finer grid spacing. In addition, a greater similarity in solutions occurred when grid spacing was refined to $1 \mathrm{~km}$ and less, with 1 - and $0.333-\mathrm{km}$ MCS cold pools more similar in magnitude, depth, length, and areal coverage, than $3-\mathrm{km}$ cold pools. The $1-\mathrm{km}$ simulations demonstrated a small increase in forecast skill for 3-h QPF throughout MCS evolution compared to 3-km runs. The 1-km MCS 9-h precipitation swaths were also better aligned with observations compared to 3-km simulations. When evaluating MCS forward propagation speeds, however, 3-km simulated MCS speeds were more similar to observations compared to $1 \mathrm{~km}$.
\end{abstract}

\section{Introduction}

Simulations of mesoscale convective system (MCS) structures and associated QPF skill have generally improved since the implementation of convectionallowing models (CAMS) in both real-case (Done et al. 2004; Weisman et al. 2008; Clark et al. 2009; Schwartz et al. 2009; Adams-Selin et al. 2013; Johnson et al. 2013; Pinto et al. 2015) and idealistic frameworks (Weisman et al. 1997; Bryan et al. 2003; French and Parker 2010; Bryan and Morrison 2012; Peters and Schumacher 2016). Previous works involving idealized cases have shown that finer horizontal grid spacing (referred to as $\Delta x$ hereafter) in CAMS allowed for the resolving of smaller-scale turbulent convective features associated with MCSs (Weisman et al. 1997; Morrison et al. 2009; French and Parker 2010; Bryan and Morrison 2012; Lebo and Morrison 2015).

Past work has shown improved structural representation of convection with simulations at $\Delta x$ finer than $6 \mathrm{~km}$ (convection allowing, without convective parameterization), compared to coarser spacing used in many larger-scale regional and global models. Weisman et al.

\footnotetext{
Corresponding author: Brian Squitieri, brianjs@iastate.edu
}

(1997) found that the better resolving of simulating squall line evolution and turbulent fluxes was more noticeable as grid spacing was refined from 12 to $1 \mathrm{~km}$ than when Bryan et al. (2003) refined grid spacing below $1 \mathrm{~km}$. Done et al. (2004) showed that 4-km WRF runs better simulated MCSs in comparison to 10-km WRF forecasts. Similarly, Kong et al. (2006), Weisman et al. (2008), and Schwartz et al. (2009) noted that simulated convective events implementing 2- and 6-km grid spacing in the WRF were superior to $12-\mathrm{km}$ NAM forecasts.

Still, questions remain regarding the benefits of simulating convection using grids finer than $4 \mathrm{~km}$, with previous research offering mixed results regarding which $\Delta x$ best simulated convection, and what model parameterizations were appropriate for a given grid spacing. Though not directly aimed at better understanding deep, moist convection, Wyngaard (2004) discussed the discrepancies of resolving turbulent flow across a range of $\Delta x$ known as terra incognita or the "grey zone," which comprised spacings from roughly $3 \mathrm{~km}$ down to a few hundred meters. In this gray zone, turbulence parameterization, applying a filter to the equations of motion, becomes inappropriate as turbulent length scales $l$ begin to overlap $\Delta x$ scales as $\Delta x$ is decreased. In Bryan et al. (2003), it was found that 1-km 
grid spacing was inadequate for resolving turbulent subconvective processes and entrainment, as convergence of squall line statistical properties was lacking even for 250- and 125-m runs, though larger deep, moist convective structures could be adequately resolved at $1-2-\mathrm{km} \Delta x$ in some cases.

Kain et al. (2008) and Schwartz et al. (2009) also noted that finer $(2-\mathrm{km})$ forecasts showed more details in convective evolution compared to 4-km runs, but with little benefit to QPF forecast skill, beckoning the question if finer grid spacing is worth the higher computational costs. Bryan and Morrison (2012) simulated an observed squall line in an idealized framework at 4-km, 1-km, and 250-m $\Delta x$ and noted that distributions of reflectivity in the convective and stratiform precipitation regions of the squall line and cold pool properties matched observations more realistically in $250-\mathrm{m}$ simulations. Lebo and Morrison (2015) showed that individual cells within an idealized squall line were narrower, more numerous in nature, and weaker as horizontal grid spacing decreased from 500 to $250 \mathrm{~m}$, as convective entrainment and detrainment became explicitly resolved and associated greater hydrometeor mixing occurred. Lebo and Morrison also found that within the perceived "grey zone" of $\Delta x$, there are subranges of spacing changes (mainly between 250 and $500 \mathrm{~m}$ ) where greater, critical differences in convective representation may occur.

Still, recent work has demonstrated some promise for improving forecasts of convection with $1-\mathrm{km}$ grid spacing. Johnson et al. (2013) showed that 1-km output demonstrated a higher similarity among objects (defined as 1-h QPF swaths) in simulations to that of observations compared to 4-km runs. VandenBerg et al. (2014) found that for short-lived, discrete storms, 1-km WRF forecasts of mean storm speeds (relative to environmental flow) matched observed storm speeds better than those from $4-\mathrm{km}$ runs, and that $1-\mathrm{km}$ storms exhibited less of a rightward bias in storm motion compared to 4-km forecasts. Potvin and Flora (2015) noted that 4-km idealized simulations (initialized from two observed soundings) were too coarse in simulating supercell evolution and storm-scale flow, with improvements in low-level rotation tracks and intensity changes noted at $1-\mathrm{km} \Delta x$. Verrelle et al. (2015) noted that $1-\mathrm{km}$ idealized supercell simulations more accurately depicted vertical velocity distributions and hydrometeors forming a well-defined hook echo compared to coarser $\Delta x$. In addition, the summation of negatively buoyant grid points at $500 \mathrm{~m}$ above ground level (AGL) showed a larger cold pool area associated with finer $\Delta x$ runs compared to coarser events, with a greater similarity in areal coverage comparing $1-\mathrm{km}$ to $500-\mathrm{m} \Delta x$ cold pool areas as opposed to 2- versus $1-\mathrm{km}$ cold pools in these idealized simulations. Schwartz et al. (2017) found that 1-km ensemble probabilistic QPFs demonstrated greater forecast skill than those at $3 \mathrm{~km}$, particularly for heavy rain events within the first $12 \mathrm{~h}$ of the simulation. In addition, the spatial placement of MCSs improved in 1- versus 3-km forecasts.

Much of the aforementioned work demonstrated the impacts that horizontal grid spacing changes had on idealized squall lines, or aggregated the results for overall model performance as $\Delta x$ changed for observed precipitating systems. Limited work has been done to show how MCS cold pool characteristics or explicitly calculated MCS forward propagation speeds changed in CAMS with varying horizontal grid spacing on a caseby-case basis. While it is understood that studying changes in simulated squall lines in an idealized framework can be helpful by reducing complexity that may be introduced from variations in the ambient and stormscale environments, it is equally important to see how $\Delta x$ changes impact real MCS cases. It may be asked for example, if finer $\Delta x$ in operational runs improve the temporal placement of simulated MCSs with a more finely resolved cold pool. The current work evaluated simulated MCS cold pools and related features for 14 observed cases using the WRF-ARW at varying convectionallowing $\Delta x$ to provide a broad analysis of simulated MCS and associated cold pool structural changes and forward propagation speeds with decreased $\Delta x$ in WRF. Explicitly calculated observed and simulated MCS speeds were used to infer if finer $\Delta x$ resolved cold pools were improving, degrading, or minimally impacting MCS forecasts given that cold pool intensity may be associated with MCS forward propagation speed (Rotunno et al. 1988). Based on the aforementioned findings of Verrelle et al. (2015) and Schwartz et al. (2017), it was hypothesized that 1-km simulated MCSs (whose cold pools would be appropriately resolved to depict larger-scale convective structures as in Bryan et al. 2003), would attain a faster forward propagation speed, perhaps better matching observed MCS speeds, with at least some improvement in QPF noted, compared to $3-\mathrm{km}$ simulated events. Furthermore, it was hypothesized that $0.333-\mathrm{km}$ simulations would add little value to improved MCS placement or QPFs, as 1- and $0.333-\mathrm{km}$ cold pools would bear greater similarity than 3- versus 1-km cold pools, analogous to the findings of Verrelle et al. (2015).

\section{Data and methodology}

\section{a. Selection process for MCS events}

All 14 MCSs selected were leading convection, trailing stratiform events originating from upscale-growing convection, developing into linear convective systems 
TABLE 1. A list of all 14 observed cases simulated in this study, with the date/time of MCS initiation, MCS longevity (measured in hours), and impacted regions of the United States provided.

\begin{tabular}{lccc}
\hline \hline \multicolumn{1}{c}{ Date } & Initiation time (UTC) & Duration (hours) & Regions impacted \\
\hline 15 Aug 2013 & 2200 & 9 & Central Plains \\
3 Jun 2015 & 0000 & 13 & Central Plains \\
7 Jun 2015 & 0000 & 16 & Upper Mississippi Valley \\
18 Jun 2015 & 0300 & 15 & Northern High Plains \\
12 Jul 2015 & 2200 & 24 & Upper Mississippi/Ohio Valleys \\
18 Jul 2015 & 0000 & 17 & Upper Mississippi Valley \\
5 Jul 2016 & 2000 & 20 & Upper Mississippi Valley \\
6 Jul 2016 & 2300 & 13 & Central Plains \\
12 Jul 2016 & 0100 & 9 & Upper Mississippi Valley \\
4 Aug 2016 & 2100 & 12 & Upper Mississippi Valley \\
16 Sep 2016 & 0200 & 9 & Southern Plains \\
18 Sep 2016 & 0400 & 14 & Southern Plains \\
15 Jun 2017 & 2000 & 9 & Southern Plains \\
16 Jun 2017 & 2100 & 14 & Upper Mississippi Valley
\end{tabular}

with a stratiform rain shield (as in Parker and Johnson 2000) or bow echoes (Przybylinski 1995). MCSs selected for study were not preceded by earlier convection downstream, nor did they merge with other MCSs at any point during evolution, similar to the requirements used in Davis et al. (2006b) and Pinto et al. (2015). MCS cases were subjectively selected via evaluations of $1 \mathrm{~km}$ AGL composite reflectivity data provided by the Multi-Radar Multi-Sensor system (MRMS) (Smith et al. 2016). Table 1 describes the 14 selected cases, including initiation date and time, longevity of MCSs (measured in hours, with initiation and dissipation time rounded off to the nearest hour), and general region of the United States impacted. MCS initiation occurred, to the nearest hour, when organized convection first achieved a continuous line of $50+\mathrm{dB} Z$ with an expanding stratiform rain shield, as in Parker and Johnson (2000). Dissipation occurred, to the nearest hour, when a leading line of $50+\mathrm{dBZ}$ echoes were no longer apparent, similar to Coniglio et al. (2010). Most MCSs initiated during the late afternoon to early evening hours, with the bulk of their life cycles taking place overnight. All MCSs occurred in the Great Plains and Upper Mississippi Valley. The goal behind evaluating isolated MCSs in relatively pristine, ambient environments was to simplify MCS analyses in a real-world environment to better understand trends in cold pool behavior, system movement, and accumulated precipitation swaths.

\section{b. Model setup}

The WRF-ARW, version 3.8 (Skamarock et al. 2008), was employed with one-way nesting to vary $\Delta x$ while appropriately establishing initial and lateral boundary conditions (ICs/LBCs), with a parent $3600 \mathrm{~km} \times$ $3600 \mathrm{~km}$ domain using 3-km horizontal grid spacing, and nested $1000 \mathrm{~km} \times 1000 \mathrm{~km}$ domains with $1-\mathrm{km}$ grid spacing, and $333 \mathrm{~km} \times 333 \mathrm{~km}$ domains using $0.333-\mathrm{km}$ grid spacing. The geographic placement of the nested domains varied for each case and was subjectively centered over regions of observed MCS evolution (e.g., Fig. 1). A large, parent 3-km domain was chosen in an attempt to minimize the downscaling impact of temporally propagating LBC errors from ICs upon the nested 1 - and $0.333-\mathrm{km}$ domains. All model configurations were initialized with 12-km NAM output (NOAA/NCDC 2015). In all simulations, for all grids, the default 50 vertical levels on terrain-following pressure coordinates were chosen. Table 2 may be consulted for more details on the WRF configurations.

The $1 \mathrm{~km}$ AGL reflectivity derived from MRMS products (Smith et al. 2016) was retrieved from the Iowa Environment Mesonet data archives (Iowa State University 2018) and was subjectively treated as ground truth for the depiction of MCS structures and evolution when model output was compared to observations.

Base variables of 1- and 0.333-km output were first filtered to exclude $2 \Delta x$ wavelengths not resolvable in $3-\mathrm{km}$ simulations, and then were regridded to $3 \mathrm{~km}$, with comparisons done only over the area covered by the smallest domain. Filtering and regridding were performed in order to compare the different grid spacing runs while maintaining fairness, as in Johnson et al. (2013). Observed composite radar data were also filtered and regridded to match the $3-\mathrm{km}$ grids when used for comparison. Three-dimensional variables used to calculate cold pools were interpolated from the WRF terrain following hybrid-sigma coordinates to constant heights AGL, from the surface to $6000 \mathrm{~m}$ (to ensure inclusion of the entire cold pool depth), at 100-m intervals. All model runs and data postprocessing were completed on the Computational and Information Systems Laboratory (CISL)-Cheyenne supercomputing system (Computational and Information Systems Laboratory 2017). 


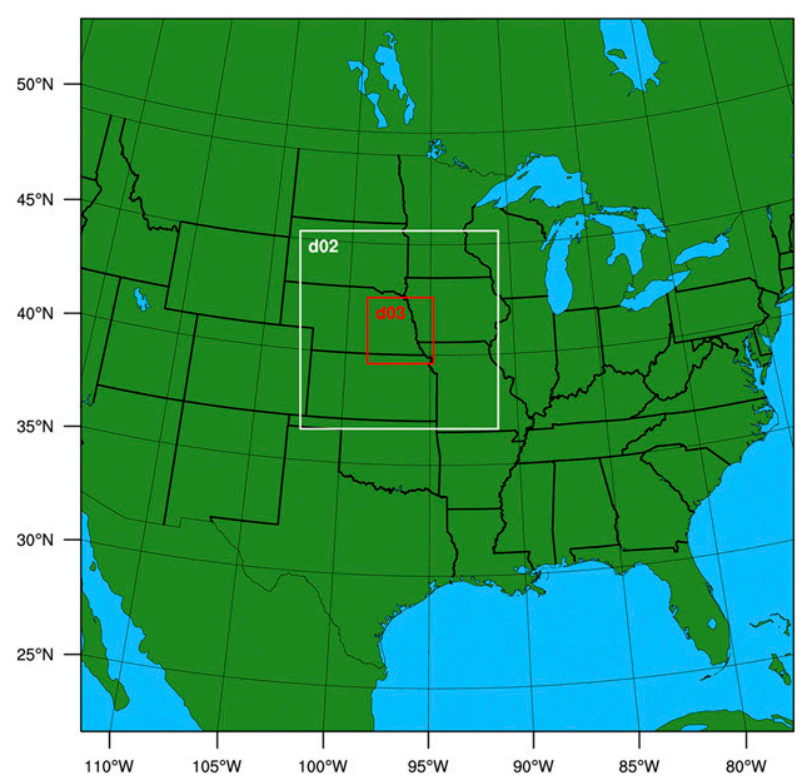

FIG. 1. One-way nested WRF domain configuration for the 17 Jun 2017 case. The map depicts all of the area covered in the parent $3600 \mathrm{~km} \times 3600 \mathrm{~km} 3-\mathrm{km}$ domain; d02, labeled in white, depicts the $1000 \mathrm{~km} \times 1000 \mathrm{~km}$ 1-km domain; and d03, labeled in red, depicts the $333 \mathrm{~km} \times 333 \mathrm{~km} 0.333-\mathrm{km}$ domain.

\section{c. Definition of the cold pool}

To better understand the nature of 3D cold pool structures, cold pool surface temperatures, depths, and the cold pool parameter $C$ were calculated. The parameter $C\left(\mathrm{~m} \mathrm{~s}^{-1}\right.$; Benjamin 1968; Rotunno et al. 1988; Weisman et al. 1988; Weisman and Rotunno 2004) is expressed by

$$
C^{2}=2 \int_{0}^{H}(-B) d z
$$

where $B$ represents buoyancy (integrated within a surface stable layer), defined as

$$
B \equiv g\left[\frac{\theta^{\prime}}{\bar{\theta}}+0.61\left(q_{v}-\bar{q}_{v}\right)-q_{c}-q_{r}\right],
$$

where $H$ in (1) delineates the top of the cold pool, also defined as the cold pool depth. In (2), $g$ is gravity, $\theta^{\prime}$ is the negative perturbation potential temperature at each model grid point, with $\bar{\theta}$ defining the representative average potential temperature of the ambient atmosphere. The water vapor, cloud water, and rainwater mixing ratios associated with each grid point representative of the cold pool were defined as $q_{v}, q_{c}$, and $q_{r}$, respectively, with $\bar{q}_{v}$ representing the average water vapor mixing ratio in the ambient atmosphere in the same manner as $\bar{\theta}$. Given that cold pool intensity should be defined
TABLE 2. Common configurations used for all WRF-ARW simulations.

\begin{tabular}{lc}
\hline \multicolumn{1}{c}{ WRF-ARW } \\
\hline Initial conditions & NAM-218 $(12 \mathrm{~km})$ grid \\
Initialization & $1200 \mathrm{UTC}$ \\
End time & $1200 \mathrm{UTC}$ \\
Total time & $24 \mathrm{~h}$ \\
Temporal output & Hourly \\
Time step $(d t)$ & $6 \mathrm{~s}$ \\
Vertical levels & 50 \\
MP scheme & Thompson \\
PBL scheme & MYJ \\
PBL surface layer & MYJ \\
Land surface & Noah LSM \\
Shortwave radiation & Dudhia \\
Longwave radiation & RRTM \\
\hline
\end{tabular}

relative to the magnitude of the ambient temperatures downstream of convection, new relative $\bar{\theta}$ and $\theta^{\prime}$ were calculated. For a given time $t$ that a simulated MCS was evaluated (Fig. 2, first row), grid point potential temperature values from the area over which the surface cold pool in the model moved through time $(t+1)$ (Fig. 2, second row) were used to calculate an averaged surface $\bar{\theta}$ value. First, surface $\Delta \theta$ was calculated by subtracting $\theta$ at $t+1$ from the value at $t$ (Fig. 2, third row). Positive surface $\Delta \theta$ values below the upper quartile were filtered out, delineating a downstream area at time $t$ representative of an ambient air mass into which an MCS is propagating (Fig. 2, fourth row). The averaged surface $\theta$ value within this constrained area was used to define surface $\bar{\theta}$, and this same area was also used to calculate $\bar{\theta}$ for all model vertical levels above the surface. Next, $\bar{\theta}$ was subtracted from $\theta$ to provide a new relative $\theta^{\prime}$, at the surface and all vertical levels aloft. These new $\bar{\theta}$ and $\theta^{\prime}$ values were then input into (2) to derive $B$. Values of $B$ less than 0 were prevalent throughout the depth of the troposphere behind MCS leading lines, so a filter was needed to cap the top of the cold pool, corresponding to the higher $B$ values, which contributed to cold pool intensity. Negative $B$ values associated only with relative $\theta^{\prime}$ less than $-3 \mathrm{~K}$ were considered for calculating cold pool depth and the $C$ parameter (as in James et al. 2005, hereafter J05). While $\mathrm{J} 05$ used $-1 \mathrm{~K}$ as the defining threshold for cold pools, J05 employed a mesoscale idealized modeling framework, simplifying the ambient environment, while the present work evaluates real-case-based events in a heterogeneous environment, introducing additional complexity (i.e., stable features that were not cold pool associated). It was determined that using the $-3-\mathrm{K}$ filter adequately capped off the top of the cold pool (typically 3-4 km AGL). Through iteration with the 

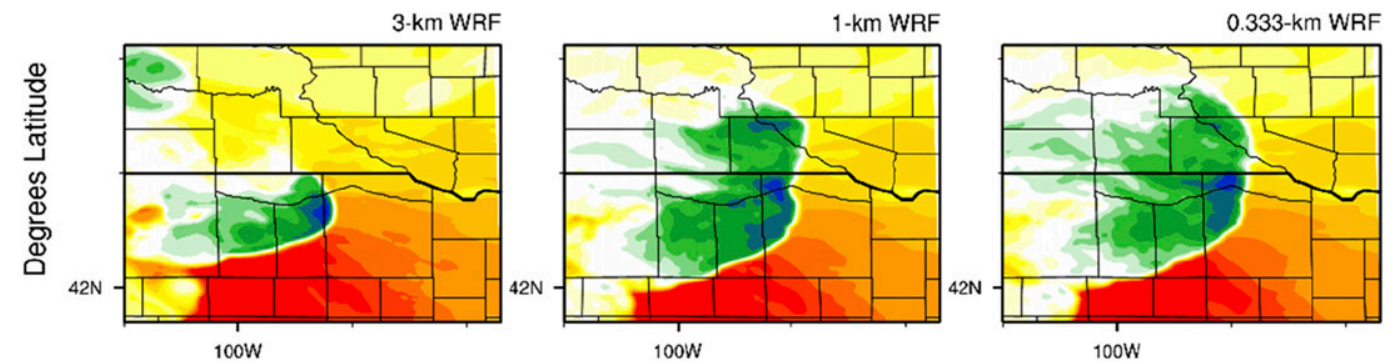

Degrees Longitude
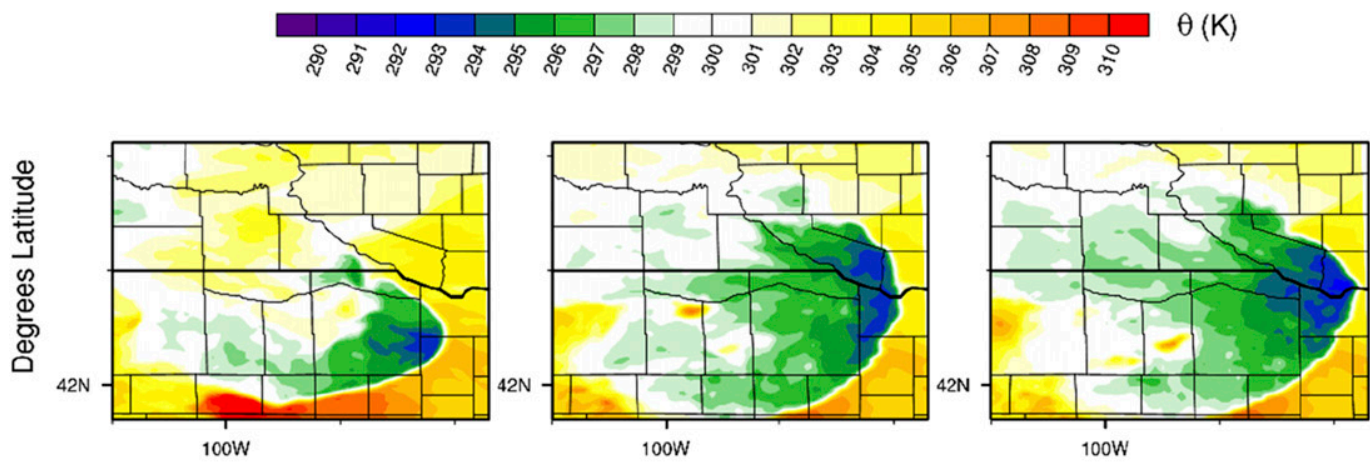

Degrees Longitude
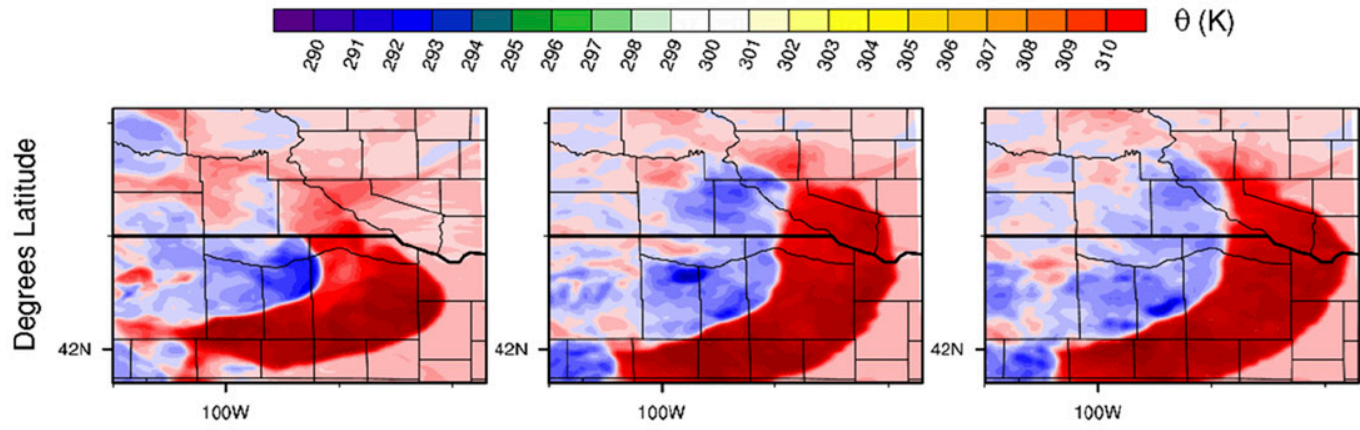

Degrees Longitude
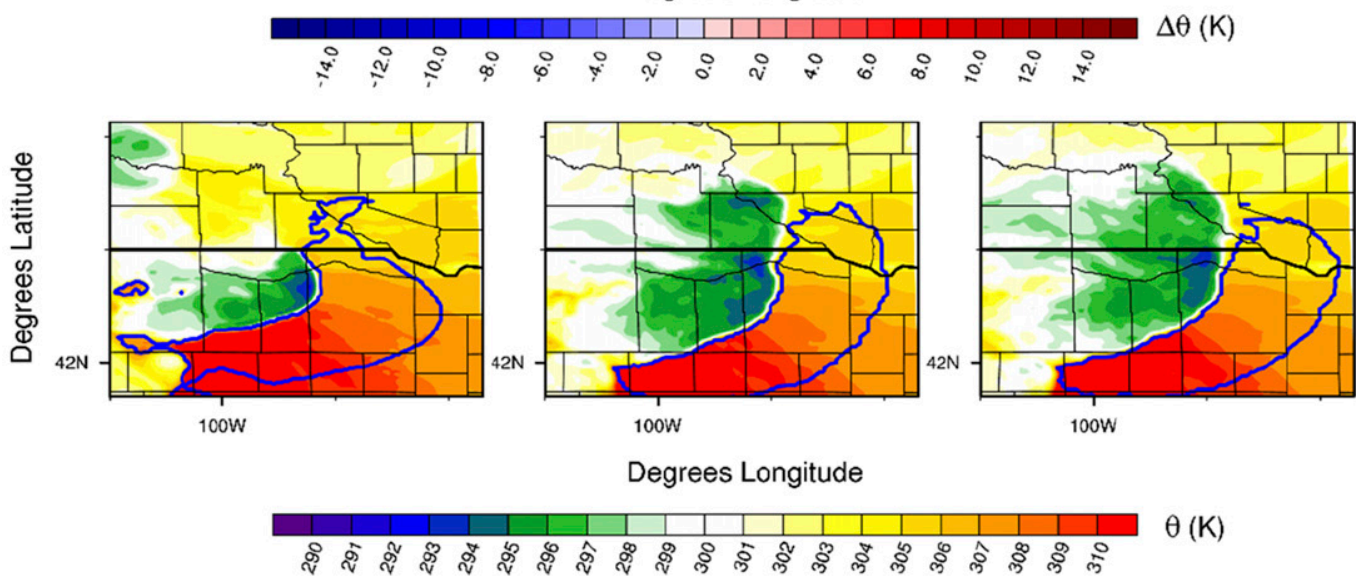

$\theta(\mathrm{K})$

FIG. 2. Simulated cold pool associated with the 7 Jul 2016 MCS event during maturity, with (left) 3-, (center) $1-$, and (right) $0.333-\mathrm{km}$ horizontal grid spacing. Surface potential temperature fields, for the evaluated time $t$ (in this case 0100 UTC) and $t+1$ (0200 UTC) are depicted (filled contours; K) in the first and second rows, respectively. The difference in the potential temperature fields $[t-(t+1)]$ is shown in the third row (filled contours; $\mathrm{K}$ ). Last, the cold pool at time $t$ is depicted by the surface potential temperature field (filled contours; K), overlaid with the top $25 \%$ positive $\Delta \theta$ values between 0100 and 0200 UTC line contoured in blue in the fourth row. 
14 simulations, testing filters ranging from $-1 \mathrm{~K}$ and colder, it was found that $-\theta^{\prime}$ values as low as $-3 \mathrm{~K}$ could be excluded without impacting the core, more stable negative $B$ values (with height), and associated $C$ magnitudes, hence capping the cold pool to a reasonable height without impacting cold pool definition beyond a very modest extent. Negative $B$ values in regions colder than the $0^{\circ} \mathrm{C}$ isotherm were also excluded so that stabilization only associated with evaporation processes were included. The remaining $B$ values were vertically integrated in (1), to produce a two-dimensional $C$ field, and the top level (with the model grid interpolated to $100 \mathrm{~m}$ AGL intervals) where remaining $B$ values were negative denoted the depth of the cold pool [H in Eq. (1)]. A mask was also used to exclude noise not representative of the cold pool. For the mask, positive $\theta^{\prime}$ values were excluded, along with negative $\theta^{\prime}$ over or adjacent to bodies of water to exclude cool, stable marine air masses not associated with convection. To ensure all cold poolbased fields were convectively induced, grid points that had not experienced maximum composite reflectivity values above $35 \mathrm{~dB} Z$ [generally representative of convection as noted in Anagnostou (2004)] at given times $t$ and $t-1$ were also excluded in the mask. The surface $\theta^{\prime}$ mask was also applied to the cold pool depth and $C$ fields.

Throughout the rest of the manuscript, negative surface $\theta^{\prime}$ and cold pool depth will be discussed multiple times and will be referred to as $-\theta_{\mathrm{sfc}}^{\prime}$ and $D$, respectively, henceforth. The absolute value of $-\theta_{\mathrm{sfc}}^{\prime}$ was used to represent cold pool magnitude for all statistical analyses.

\section{d. Use of Stage-IV data to verify forecasts}

To also examine the impact of decreased $\Delta x$ on precipitation, observed precipitation swaths were evaluated using Stage-IV data (NCAR/UCAR/EOL 2015). The Stage-IV data were trimmed down to the smallest WRF domains evaluated for each case (i.e., $1 \mathrm{~km}$ ) in order to focus on the areas impacted by the observed and simulated MCSs only. The 3- and 1-km WRF output were filtered and regridded to $4 \mathrm{~km}$ to match Stage-IV gridded observations. $0.333-\mathrm{km}$ simulations were excluded from tasks involving QPF evaluations because the $0.333-\mathrm{km}$ domains were too small to capture longer periods of MCS evolution for comparisons to be made with observations, as MCSs either initiated outside of the domain, or propagated outside of the domain well before weakening or dissipating. Neighborhood (Clark et al. 2010) equitable threat scores (nETSs) were calculated to determine the forecast skill of 3- and 1-km quantitative precipitation forecasts (QPFs). While both Clark et al. (2010) and Squitieri and Gallus (2016) used a 60-km radius of influence to sum contingency table elements (hits, misses, false alarms, and correct negatives), the current work evaluated QPF swaths at varying radii of influence $(30,60$, and $120 \mathrm{~km})$, with precipitation thresholds of $2.54,6.35$, and $12.70 \mathrm{~mm}(0.10,0.25$, and $0.50 \mathrm{in}$.) to evaluate sensitivity in nETS calculations.

\section{e. Use of MODE for simulated cold pool comparisons}

The Method for Object-Based Diagnostic Evaluation tool (MODE; Davis et al. 2006a, b) was used to compare simulated cold pool structures from varying $\Delta x$ runs and was applied to $C$ to compare simulated mature MCS cold pools, as in Schwartz et al. (2017). Runs with the finest grid spacing $(0.333 \mathrm{~km})$ were treated as "control runs," and cold pool characteristics from these control runs were compared to those from the coarser runs to determine similarity between cold pool structures with varying $\Delta x$. MODE employs a fuzzy-logic approach to identify and compare objects (typically observed versus simulated) derived from features depicted by data within a gridded framework (Bullock et al. 2016). Traditionally, MODE has been used to compare observed versus forecast accumulated precipitation tracks to verify QPFs (Davis et al. 2006a,b, 2009; Gallus 2010). However, objectoriented techniques have been used for nonaccumulated variables, such as reflectivity signatures, using the contiguous rain area (CRA) technique as in Gallus and Pfeifer (2008), and drought variables like the standardized precipitation or evapotranspiration indices as in Abatan et al. (2018).

To appropriately define and identify cold pool objects in $0.333-, 1-$, and 3-km runs and compare them, multiple parameters were configured in MODE that produced results agreeing best with subjective evaluation of several cases. A circular convolution-smoothing radius of 5 grid squares or $15 \mathrm{~km}$ in length (with each grid square representing a $3 \mathrm{~km} \times 3 \mathrm{~km}$ area) was chosen in order to identify cold pools large enough to be associated with MCS structures, without excluding smaller, secondary segments of $C$ values that were still associated with the MCS. To account for spatial displacements of MCS cold pools in varying $\Delta x$ runs, a maximum centroid distance (defined as the maximum distance between the centroids of two compared objects) of $300 \mathrm{~km}$ was used to determine if cold pool objects in the coarser runs were related to those in the $0.333-\mathrm{km}$ MCS control runs (as in Davis et al. 2006a).

\section{f. Bootstrap resampling for testing statistical significance}

Given the small sample sizes to be compared throughout this work, a bootstrap resampling method 

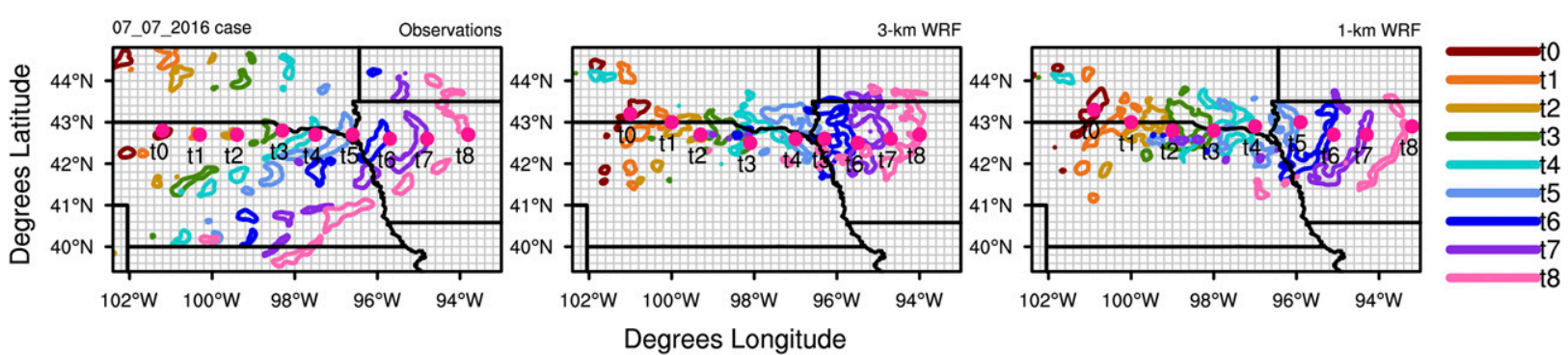

FIG. 3. (left) Observed, (center) 3-km, and (right) 1-km WRF simulations of MCS evolution for the 7 Jul 2016 case, as shown by subjectively smoothed line contours of $35-\mathrm{dBZ} 1 \mathrm{~km}$ AGL reflectivity, with each hour of MCS evolution depicted with a different color (see color bar at right). Pink circular markers indicate the subjectively defined representative MCS locations from which MCS hourly averaged forward propagation speeds were derived, with t0 being the time of MCS initiation, through t8, the last time the MCS location was recorded. Please refer to section $2 \mathrm{~g}$ for details on how MCS locations and associated hourly averaged forward propagation speeds were derived.

was employed to determine statistical significance. For all comparisons, the bootstrap resampling employed a two-tailed test to determine if values in one sample were significantly stronger/weaker or bigger/smaller to the compared values of another sample. The associated $t$-test statistic was calculated, with random sampling occurring 10000 times. The achieved level of significance (an estimated $p$ value) was then derived to determine statistical significance (Mendenhall and Sincich 2007).

\section{g. Documenting of MCS temporal evolution}

Observed and simulated MCS evolution was documented hourly to explicitly calculate MCS forward propagation speeds. Nine different hours were evaluated for each MCS, with the first time being ' $t 0$,' representing the time of MCS initiation (as described in section $2 \mathrm{a}$ ) and the last time being "t8." Only $8 \mathrm{~h}$ after initiation were considered given temporally limited model output (out to 1200 UTC, or $24 \mathrm{~h}$ after model initialization), and MCS weakening trends noted in WRF output (discussed more in results). Times t0-t8 for observed and simulated ( 3 and $1 \mathrm{~km}$ ) MCSs were calculated separately for independent evaluation. MCS initiation times ( 0 ) were the same among varying $\Delta x$ runs for all cases, allowing for straightforward comparisons. Temporal displacements in simulated MCSs with respect to observations, however, were noted. When calculating nETSs (taking into account spatial/temporal model QPF displacements), the observed $\mathrm{t} 0-\mathrm{t} 8$ times were chosen to evaluate both observations and model output to deduce model skill in QPFs.

Observed and simulated hourly MCS propagation speeds were explicitly calculated and compared for $8 \mathrm{~h}$ of MCS evolution (see Fig. 3 for an example case), with the starting time at $1 \mathrm{~h}$ past MCS initiation (t1). First, for each hour of observed and simulated MCS evolution, a grid point was chosen to represent the leading edge of the MCS with the aid of a $0.20^{\circ}$ latitude $\times 0.20^{\circ}$ longitude grid. The $1 \mathrm{~km}$ AGL reflectivity fields were used to determine propagation speed in place of cold pool variables so that direct comparisons could be made with high-resolution observations. Representative grid points were chosen either along the centermost portion of the line, or where leading line convection was most intense, identified by a sharp leading-line reflectivity gradient, with $35+\mathrm{dB} Z$ values denoting convective cores (Rosenfeld et al. 1994). On occasion, the MCS cold pools would outrun the main line of convection (often delineated by a narrow, broken band of $20-35-\mathrm{dBZ}$ reflectivity displaced up to $10-30 \mathrm{~km}$ ahead of the linear band of convective cores, often noted in both observations and simulations). In these cases, the representative grid point would be placed in the center of, or in the most intense (i.e., apex of a bowing segment) portion of the line. As the outrunning cold pool leading edges were more difficult to detect with the aforementioned weaker reflectivity ahead of the main convective band, true propagation speeds may be up to $1 \mathrm{~m} \mathrm{~s}^{-1}$ faster or slower than those computed, but this difference is small enough that it does not affect results. Next, the great circle or true surface distance between the grid points for the current and previous hour of analysis was calculated on a $2 \mathrm{D}$ curvilinear grid, with the resultant value divided by $3600 \mathrm{~s}$ to estimate the MCS forward propagation speed.

Similar to the aforementioned QPF evaluations, the $0.333-\mathrm{km}$ MCSs were excluded from this particular task, as multiple hours of MCS development (i.e., $\mathrm{t} 0-\mathrm{t} 3$ for some cases), and evolution of later stages (i.e., t6-t8 for example), occurred outside of the $0.333-\mathrm{km}$ domain. 

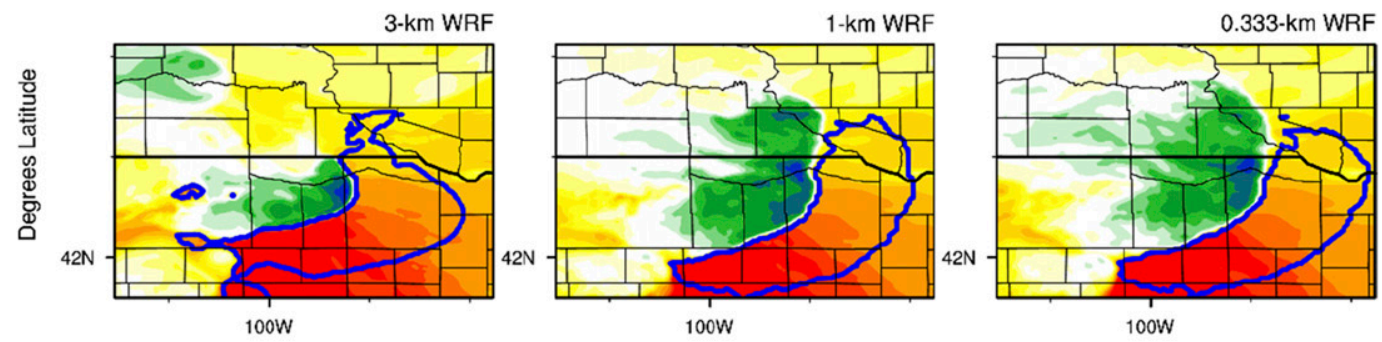

Degrees Longitude

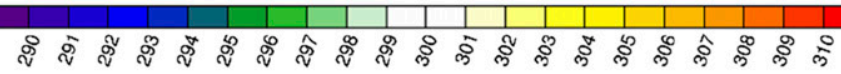
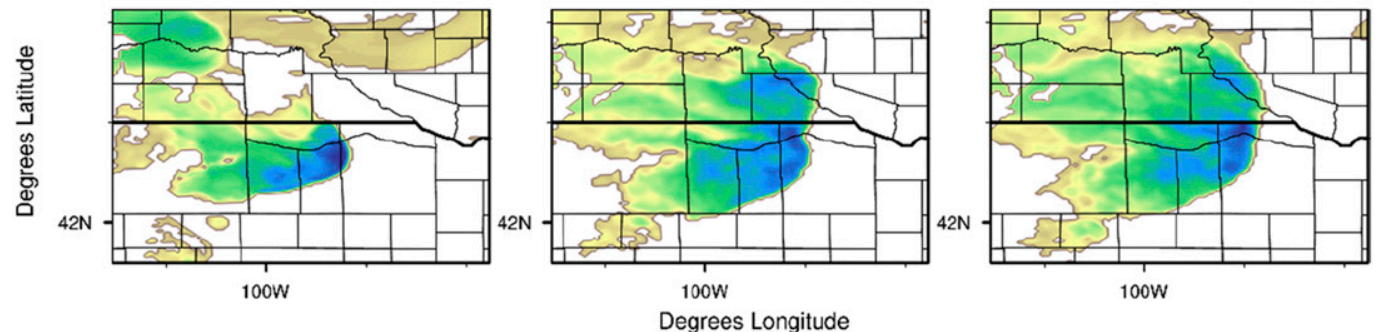

Degrees Longitude

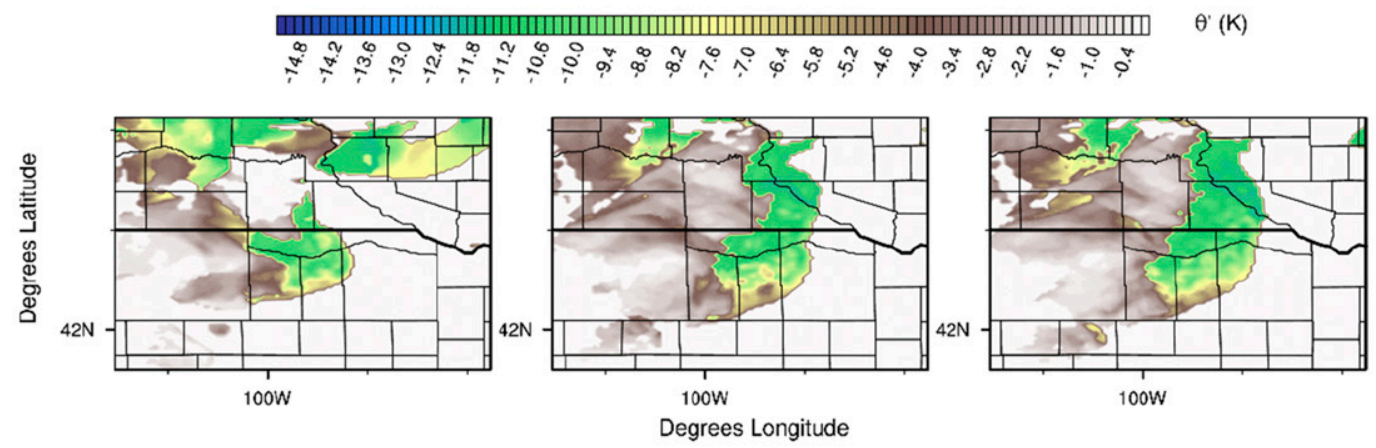

س

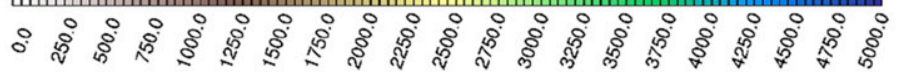

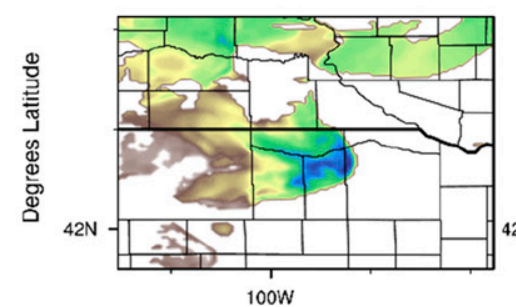

$100 \mathrm{~W}$

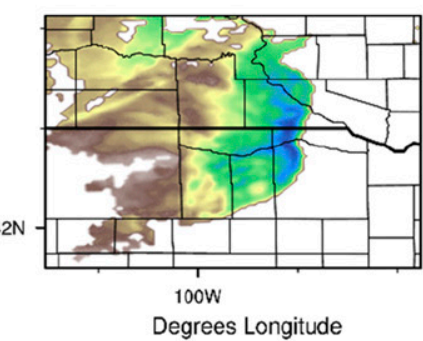

Degrees Longitude

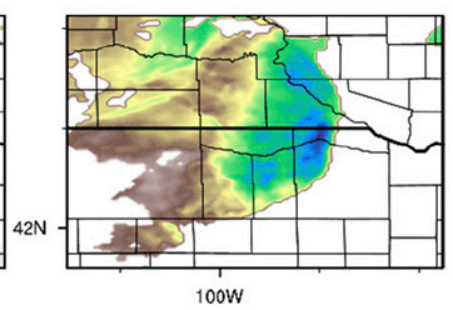

$\mathrm{C}\left(\mathrm{m} \mathrm{s}^{-1}\right)$

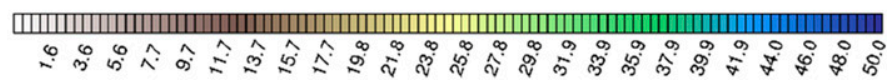

FIG. 4. Simulated cold pool associated with the 7 Jul 2016 MCS event during maturity, at 0100 UTC, with (left) 3-, (center) 1-, and (right) $0.333-\mathrm{km}$ horizontal grid spacing. The cold pool is depicted by the surface potential temperature field (filled contours; $\mathrm{K}$, with the top $25 \% \Delta \theta$ values between 0100 and 0200 UTC line contoured in blue) in the first row, $-\theta_{\text {sfc }}^{\prime}$ field (filled contours; K) in the second row, $D$ (filled contours; m AGL) in the third row, and $C$ (filled contours; $\mathrm{m} \mathrm{s}^{-1}$ ) in the fourth row. Values of $-\theta_{\mathrm{scc}}^{\prime}, D$, and $C$ were shown only where $-\theta_{\mathrm{sfc}}^{\prime}<-6 \mathrm{~K}$ for the sake of figure clarity. 


\section{Results}

\section{a. Differences in simulated mature cold pool} characteristics with decreased grid spacing

MCS maturity was subjectively classified as a welldefined MCS, $3-5 \mathrm{~h}$ after clustering convection resulted in relatively continuous lines of $50-\mathrm{dB} Z$ cores, with maturation of a stratiform precipitation shield noted, similar to the mature stages of MCSs classified in Parker and Johnson (2000). The median and 75th, 90th, and 99th percentiles of cold pool variable magnitudes were calculated for significance testing, with values less than these thresholds excluded. The magnitudes of the remaining values were then averaged to a single value, with the area recorded. Magnitudes were then bootstrap resampled to compare 3- versus $1-\mathrm{km}, 3$ - versus $0.333-\mathrm{km}$, and 1 - versus $0.333-\mathrm{km}$ simulations. The aforementioned percentiles were subjectively chosen to sample cold pools that were averaged with varying degrees of intensity distribution (i.e., how do cold pool statistics change when averaging over most of the cold pool, or over the core (colder, deeper parts) of the cold pool). Given the aforementioned constraints to the $D$ and $C$ fields based on the applied $-\theta_{\text {sfc }}^{\prime}$ filters (hence the similarity in areal coverage between these fields), and given that $C$ is the focus in this work, only the areal coverage of $C$ will be evaluated henceforth (with areal coverage significance testing reserved for the MODE tasks).

Mature MCS cold pools were larger, and had overall faster forward propagation speeds in the 1- and $0.333-\mathrm{km}$ simulations compared to the $3-\mathrm{km}$ runs by the mature stage of MCS evolution (Fig. 4), concurring with assessments made by Schwartz et al. (2017). When evaluating areal coverage (number of grid points times $3 \mathrm{~km} \times 3 \mathrm{~km}$ or $9 \mathrm{~km}^{2}$ ) of the $C$ fields (Fig. 5), 1- and 0.333-km simulated MCS cold pools were more expansive than $3 \mathrm{~km}$, regardless of the threshold for which values of $C$ were included. With $-\theta_{\mathrm{sfc}}^{\prime}, D$, or $C$ magnitudes, however, 1 - and $0.333-\mathrm{km}$ cold pools were only slightly colder and deeper than $3 \mathrm{~km}$ when incorporating a lower inclusivity threshold (median and 75th percentiles) for averaging grid points to represent an MCS (Fig. 6), with no statistical significance noted (Table 3). When increasing the inclusivity thresholds to the 90th and 99th percentiles (sampling the core of the cold pool-Fig. 6), 3-km cold pools were colder and deeper than 1 or $0.333 \mathrm{~km}$, also evident when evaluating the apex of the bowing structure for all grid spacings exemplified in the 7 July 2016 case (Fig. 4). However, 3-km cold pools were only statistically significantly (or near significantly) colder or deeper than the finer $\Delta x$ runs when using
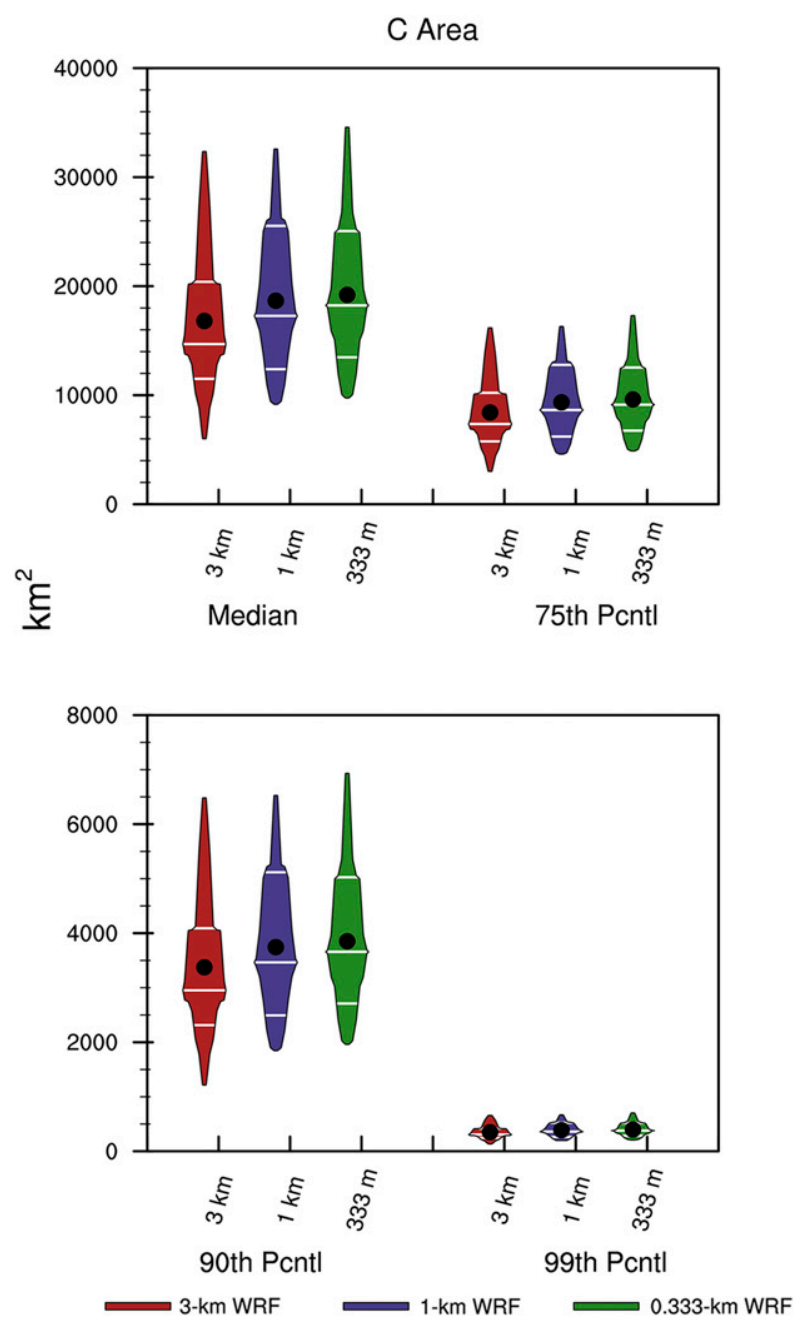

FIG. 5. Violin plots showing the average (black dots) and distribution (filled, colored contours) of the $C$ areal coverage for all 14 cases in 3-, 1-, and 0.333-km simulations, at subjectively chosen times of MCS maturity. For each case, magnitudes were calculated by averaging a value for all grid points exceeding the median and 75th, 90th, 99th percentile thresholds. Areal coverage was determined by summing all grid points exceeding the aforementioned thresholds. Please note the change in $y$-axis values between the top and bottom plots, which separate the area distributions for the (top) median and 75th percentile and (bottom) 90th and 99th percentiles.

the $90 \%$ confidence interval for significance testing (Table 3).

The $C$ magnitudes were binned for a spectrum of percentiles, from the lower 10th percentile, to the upper 10th percentile, for all 14 cases. For example if the median value of a $C$ field was $20 \mathrm{~m} \mathrm{~s}^{-1}$ and the upper one-third percentile value was $30 \mathrm{~m} \mathrm{~s}^{-1}$, then all grid points with values in the $20-30 \mathrm{~m} \mathrm{~s}^{-1}$ range would be binned into a single category, as exemplified in Fig. 7 (top) with multiple bins for the 7 July 2016 case for the 
$\theta$ ' Magnitudes

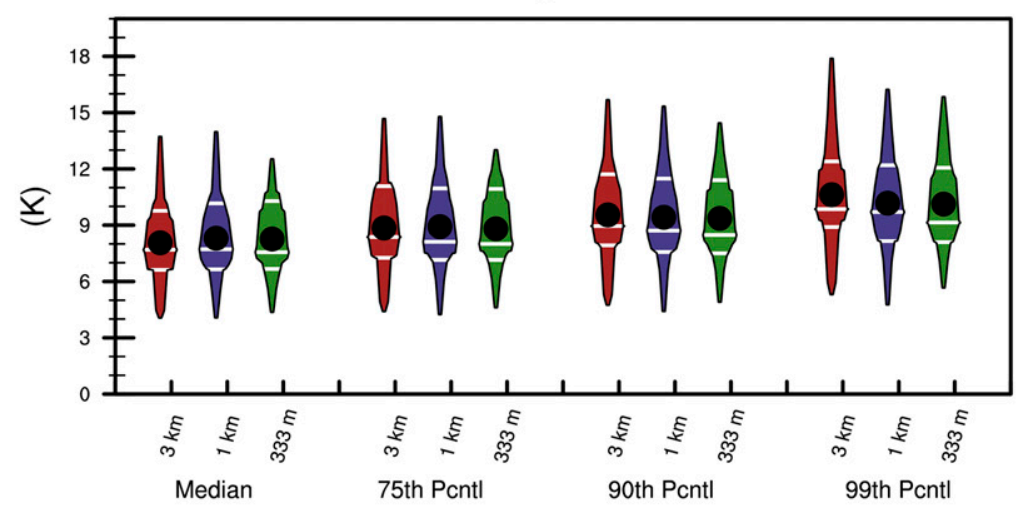

Depth Magnitudes

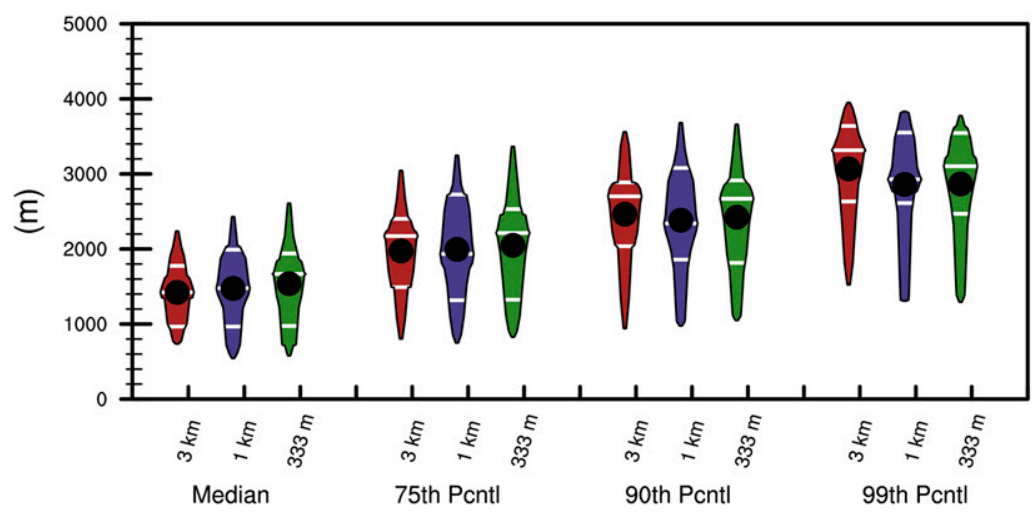

C-Parameter Magnitudes

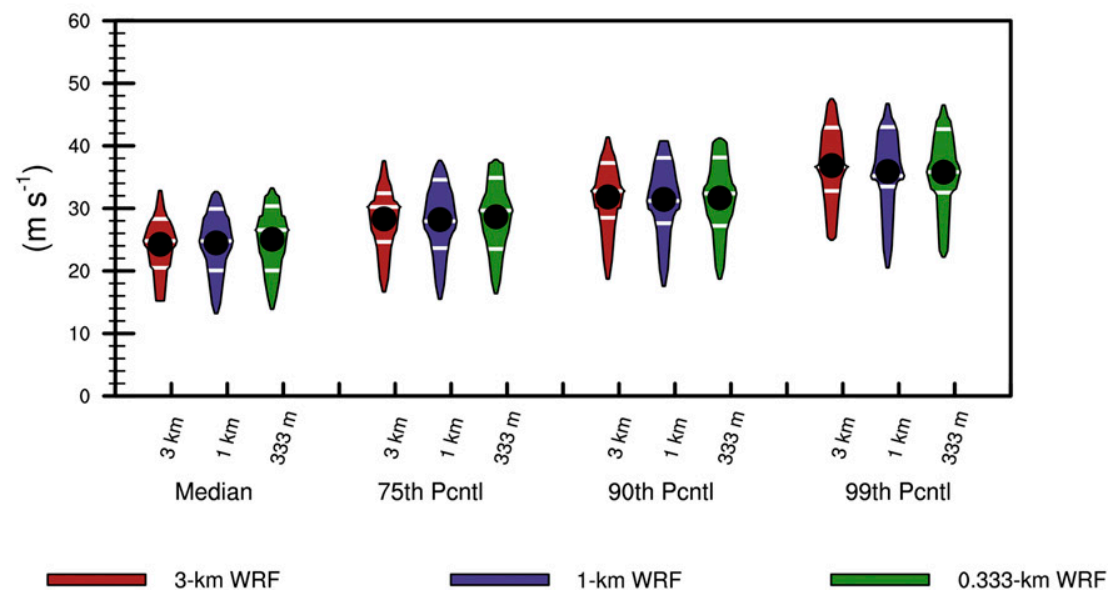

FIG. 6. As in Fig. 5, but for the evaluation of the absolute value of $-\theta_{\mathrm{sfc}}^{\prime}, D$, and $C$ magnitudes.

1-km $C$ field. The binned $C$ values for all cases (Fig. 7-bottom), for all $\Delta x$ runs, were then aggregated and averaged to a single histogram (Fig. 8) for comparison. No significant differences in magnitudes within bin categories were observed with $C$ fields between 1and $0.333-\mathrm{km}$ grid-spaced events, as greater similarity in solutions between the finer $\Delta x$ runs occurred in all cases, supporting conclusions drawn by Verrelle et al. (2015), who found that a greater similarity existed between $1-\mathrm{km}$ and $500-\mathrm{m}$ simulated cold pools compared to runs with coarser $\Delta x$. Exemplified by the 7 July 2016 case (Fig. 4; second and third columns), a 
TABLE 3. Bootstrap resampling-derived achieved level of significance ( $p$ values) for differences between 3- and 1-km, 3- and $0.333-\mathrm{km}$, and 1 - and $0.333-\mathrm{km}$ averaged cold pool $-\theta_{\mathrm{sfc}}^{\prime}, D$, and $C$ magnitudes. Values were averaged for all grid point magnitudes, in all cases, exceeding the 75th, 90th, and 99th percentiles. Italicized values below 0.10 represent statistically significant values via the $90 \%$ confidence interval.

\begin{tabular}{rccc}
\hline \hline ASL & 3 to $1 \mathrm{~km}$ & 3 to $0.333 \mathrm{~km}$ & 1 to $0.333 \mathrm{~km}$ \\
\hline 75th percentile & & & \\
$\theta^{\prime}$ magnitude & 0.736 & 0.604 & 0.629 \\
$D$ magnitude & 0.862 & 0.423 & 0.295 \\
$C$ magnitude & 0.869 & 0.606 & 0.136 \\
90th percentile & & & \\
$\theta^{\prime}$ magnitude & 0.582 & 0.623 & 0.791 \\
$D$ magnitude & 0.383 & 0.655 & 0.495 \\
$C$ magnitude & 0.516 & 0.741 & 0.452 \\
99th percentile & & & \\
$\theta^{\prime}$ magnitude & 0.114 & 0.091 & 0.864 \\
$D$ magnitude & 0.135 & 0.206 & 0.901 \\
$C$ magnitude & 0.169 & 0.089 & 0.757 \\
\hline
\end{tabular}

strong qualitative similarity between the finer gridspaced simulated cold pool variables with regard to magnitude distribution, and cold pool structure existed. Similarly, Fig. 8 shows strong similarity of magnitude frequency distributions of $C$ for 1 versus $0.333 \mathrm{~km}$ compared to 3 versus $1 \mathrm{~km}$ or 3 versus $0.333 \mathrm{~km}$. To provide a more sophisticated analysis of cold pool structures among varying $\Delta x$, MODE was used. Metrics calculated from MODE for each case were also bootstrap resampled to determine statistical significance of differences in MCS cold pool characteristics between varied $\Delta x$ solutions.

MCS cold pools in 1-km runs were statistically significantly longer (i.e., the line parallel length) (Table 4) compared to $3 \mathrm{~km}$ (Fig. 9), though 1 - and $0.333-\mathrm{km}$ cold pools were more similar in length on average, with a slightly smaller span in length magnitudes between the finer $\Delta x$ runs for all cases. In comparisons of 3- to 1-km, 3 - to $0.333-\mathrm{km}$, and 1 - to $0.333-\mathrm{km}$ runs, the cold pools in the finer grid spacing runs were statistically significantly larger than in the coarser runs (Table 4), with a smaller span among the area distributions of all 14 cases in finer $\Delta x$ runs also noted (Fig. 9). When $0.333-\mathrm{km}$ cold pool simulations were employed as 'control runs', the displacements of the cold pool centroids in the $1-\mathrm{km}$ solutions were statistically significantly smaller (Table 5) compared to those for the $3-\mathrm{km}$ solutions (Fig. 10), meaning significantly more agreement exists in the spatial placement of MCS cold pools between the finer $\Delta x$ runs. Similarly, symmetric differences (or differences in shape) in cold pool structures were smaller between 1 - and $0.333-\mathrm{km}$ solutions compared to 3 versus
$0.333 \mathrm{~km}$, with agreement among the finer grid-spaced solutions being statistically significantly higher compared to 3 versus $0.333 \mathrm{~km}$ (Table 5). Less change was observed in differences of cold pool orientation angles in 1 - versus $0.333-\mathrm{km}$ compared to 3 - versus $0.333-\mathrm{km}$ comparisons, and consequently, the agreement of 1versus $0.333-\mathrm{km}$ angle differences was statistically significantly higher than that for the 3 - versus $0.333-\mathrm{km}$ comparisons, best qualitatively exemplified in the last column of Fig. 11, where 1- and $0.333-\mathrm{km}$ simulated MCSs for multiple cases at their mature stage were all oriented in roughly the same direction. The 1 - and 0.333 $\mathrm{km}$ cold pools were more similar in total areal coverage (Table 5, Fig. 10; area ratios) than those in the 3-versus $0.333-\mathrm{km}$ runs. In addition, given that spatial displacements between 1 - and $0.333-\mathrm{km}$ cold pools were smaller than those between 3 and $0.333 \mathrm{~km}$, there was a statistically significantly higher overlap between 1 - and $0.333-\mathrm{km}$ cold pool areas compared to $3-$ and $0.333-\mathrm{km}$ solutions. These overlap tendencies may be noted by comparing the normalized intersection area magnitudes, as well as the ratio of the intersection area to the overall areas of either object (Fig. 10), with statistically significantly higher agreement (Table 5) noted with 1 - versus $0.333-\mathrm{km}$ comparisons than for 3 versus $0.333 \mathrm{~km}$. The smaller range in distribution of values associated with the finer versus coarser $\Delta x$ runs also suggests that less case to case variability in simulating MCS structures may be expected when employing grid spacings finer than $1 \mathrm{~km}$. Holding all else constant, it may be concluded that subkilometer simulations would hold little value in an operational setting for simulating larger-scale storm complexes such as MCSs.

\section{b. MCS forward propagation speed changes with decreased horizontal grid spacing}

While $C$ fields, representing simulated MCS cold pools among $\Delta x$ simulations, were similar in size during the early stages of evolution (exemplified for 3 cases in Fig. 11, column 1), trends representing more expansive cold pools in finer $\Delta x$ simulations manifested later (Fig. 11, columns 2-4). As noted in Fig. 4 and exemplified in most of the 14 other cases (as in Fig. 11, columns 3-4), mature simulated MCSs in the finer grid spaced runs exhibited more bowlike features, potentially indicative of faster propagating MCSs. Finer grid-spaced MCSs had a tendency to accelerate slightly ahead of their 3-km counterparts as MCS cold pools began to mature, usually within a few hours of initiation. Most 1and $0.333-\mathrm{km}$ MCSs moved at roughly the same speeds. While some differences in cold pool areal expansions were noted in comparisons of 1 - versus $0.333-\mathrm{km}$ runs, 

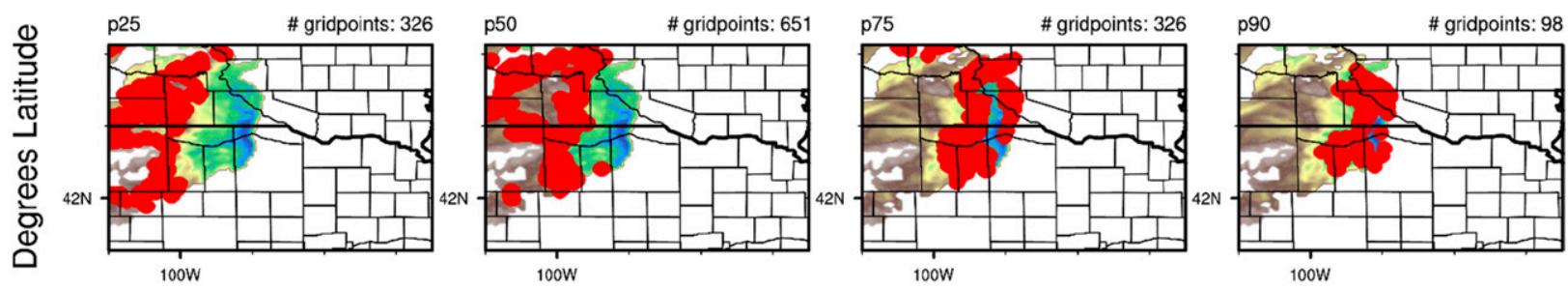

Degrees Longitude
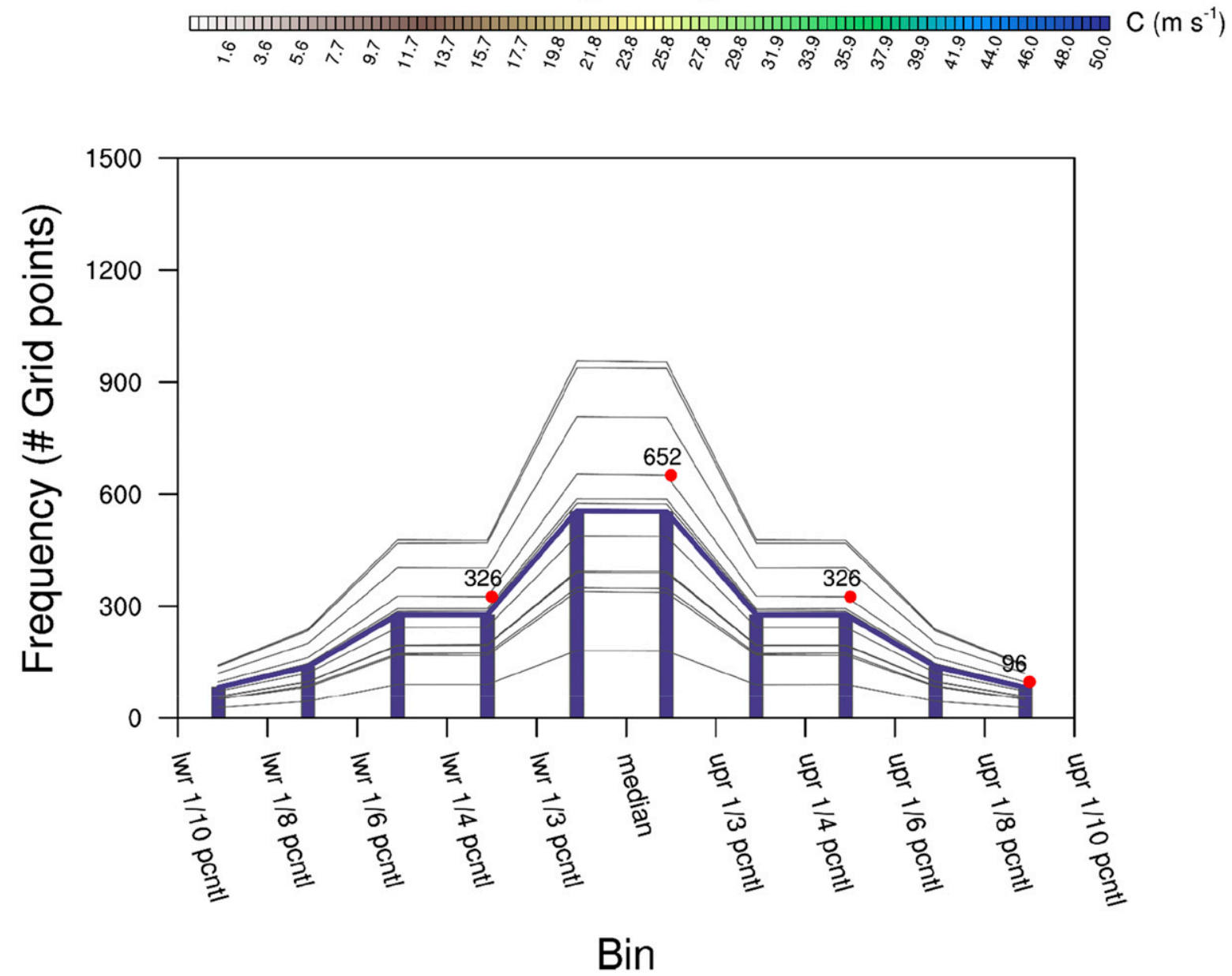

FIG. 7. (top) The $C$ magnitudes (filled contours; $\mathrm{m} \mathrm{s}^{-1}$ ) for the $7 \mathrm{Jul} 2016$ case at 0100 UTC, overlaid with red filled contours highlighting the specific grid points that, from left to right, fall into the lower 1/4-1/3 (p25), median-upper 1/3 (p50), upper 1/4-1/6 (p75), and upper 1/8$1 / 10$ (p90) percentile bins, respectively. Each percentile bin and associated grid point count is located at the top of each plot. (bottom) A histogram, depicting the averaged distribution for all 14 cases (blue line and bars) is overlaid on top of the 7 Jul 2016 bin shown in the top example plot (red dots), and the other 13 cases, shown via thinner gray lines.

more agreement in overall MCS size and spatial overlap was present between 1 - and $0.333-\mathrm{km}$ cold pools than between 3- and $0.333-\mathrm{km}$ cold pools throughout much of the MCS evolution. The greater similarity in solutions (i.e., speed, areal coverage, and intensity) between 1and $0.333-\mathrm{km}$ MCSs, with the greater differences in speed noted mainly between 3 and $1 \mathrm{~km}$, suggests that fundamental differences in resolving convection exist in operational models somewhere between 3 - and $1-\mathrm{km}$ spacings, concurring with other studies of convection simulated within the terra incognita, as in Verrelle et al. (2015).

Little work has been done to explicitly document and statistically compare MCS forward propagation speed changes with decreased $\Delta x$, a task recommended by Schwartz et al. (2017). As shown in Fig. 12, the greatest spread of averaged forward propagation speeds (based on quartiles or the entire distribution of cases) occurred 


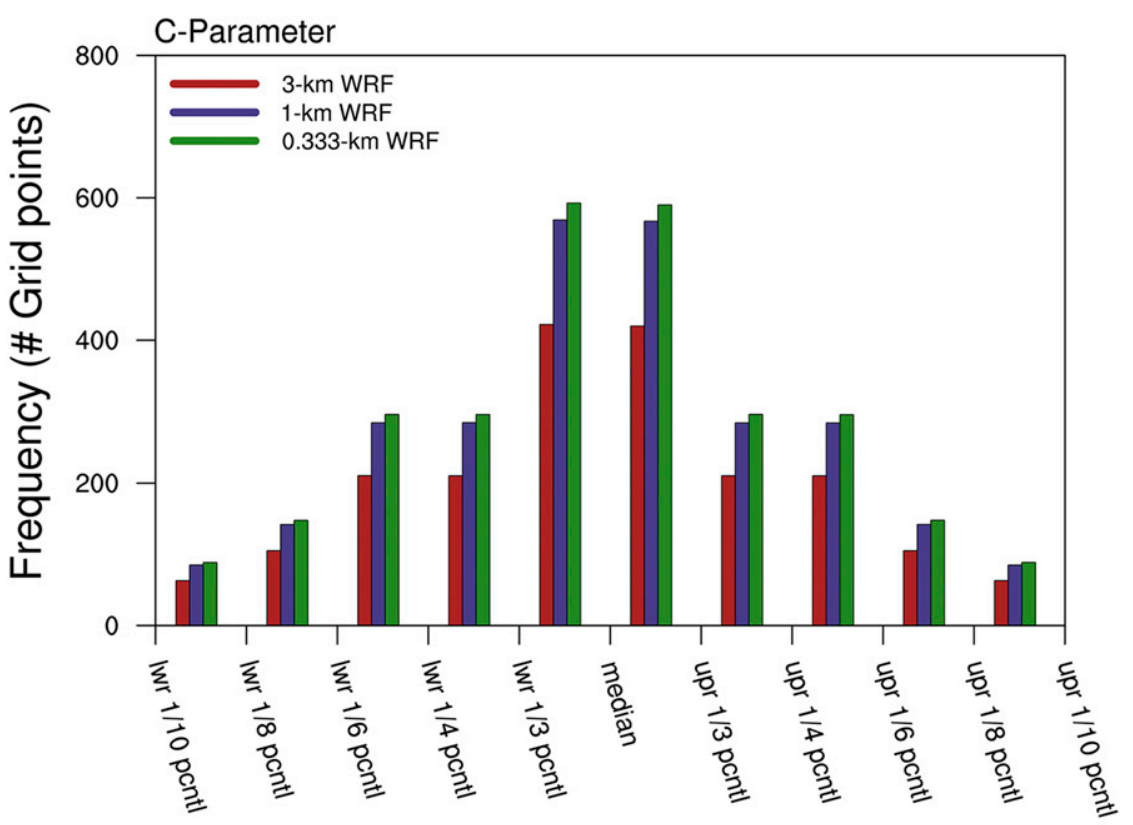

Bin

FIG. 8. Histogram averaging the binned distributions of $C$ magnitudes for all 14 cases (shown in Fig. 7), for 3-, 1-, and 0.333-km simulated cold pools. Statistics for each case were collected for one time during MCS maturity.

in the first hour of MCS initiation, as MCSs were still organizing cold pools (see first two columns in Fig. 11) and had yet to achieve mature structures. From t2-t4 (Fig. 12), many of the 14 observed and simulated MCSs began to undergo rapid organization, where an overall increase in propagation speeds, and a general decrease in spread among the aforementioned MCS speeds, was noted (evident via evaluation of the quartiles or distribution of all cases). It is possible that, for a few cases, some error in denoting forward propagation speed during the first few hours of MCS life cycles was introduced, as a few MCSs may have moved downstream via new cellular development or discrete propagation. From around 44 onward (Fig. 12), observed and simulated MCSs achieved maturity (not explicitly shown, with MCS maturity defined in the same manner as earlier), with most MCSs expanding in size while exhibiting bowlike structures (Fig. 11). From roughly t4 to t6, simulated MCSs peaked in forward propagation speed, with an overall decrease in hours $\mathrm{t} 7-\mathrm{t} 8$ (evident when evaluating average simulation speeds or quartile ranges). Observed MCSs, however, continued to increase in forward propagation speed up to $t 8$, where most simulated MCSs dissipated or were weakening, while observations showed a mature MCS still highly organized, propagating relatively rapidly downstream, evident via $1 \mathrm{~km}$ AGL reflectivity signatures of continuous 45-50-dBZ linear, bowing structures (not shown).
When comparing observed MCS forward propagation speeds to simulations, average $3-\mathrm{km}$ MCS speeds better matched observations compared to $1 \mathrm{~km}$ for all hours except $\mathrm{t} 4$ and $\mathrm{t} 7$ (Fig. 12). Still, comparisons of simulated MCS propagation speeds to those observed are not as straightforward. For example, at $\mathrm{t} 5-\mathrm{t} 6$, the 3-km average MCS speed better matched the average for observations, but the spread among the total distribution and quartile subset of $1-\mathrm{km}$ speeds was more similar to the spread of the total distribution and quartile subranges of observations than 3-km results. For t7, 1-km-averaged speeds, quartile subrange speeds, and speed spread among the distribution of cases better represented observations than $3 \mathrm{~km}$. At t8, 3-km-averaged speeds were slightly higher than $1 \mathrm{~km}$ (thus slightly more similar to observations), but the spreads among the inner quartile range and distribution of all cases for $1 \mathrm{~km}$

TABLE 4. As in Table 3, but for MODE-derived statistics based on objects identified in the $C$ field as MCS cold pools. Boldfaced ASL values (below 0.05) are considered statistically significant via the $95 \%$ confidence interval.

\begin{tabular}{lccc}
\hline \hline ASL & 3 to $1 \mathrm{~km}$ & 3 to $0.333 \mathrm{~km}$ & 1 to $0.333 \mathrm{~km}$ \\
\hline Length & $\mathbf{0 . 0 2 5}$ & $\mathbf{0 . 0 0 3}$ & 0.095 \\
Area & $\mathbf{0 . 0 3 8}$ & $\mathbf{0 . 0 2 4}$ & 0.375 \\
\hline
\end{tabular}




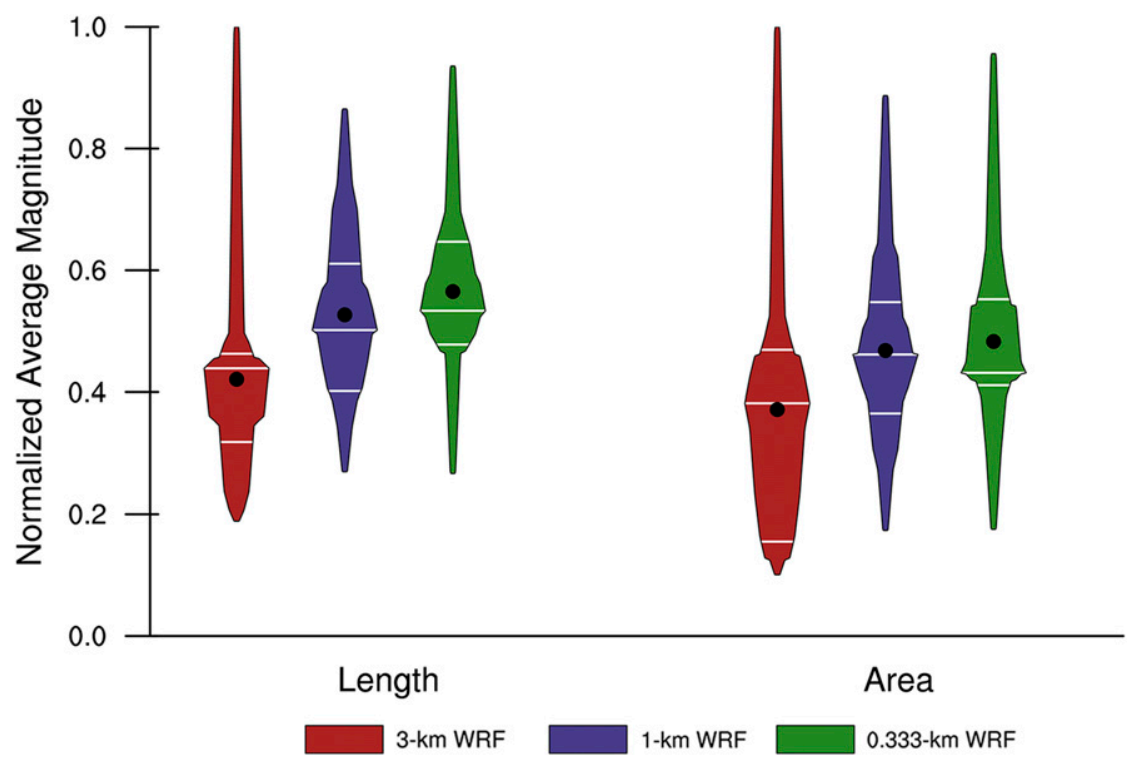

FIG. 9. Violin plot showing the average (black dots) and distribution (filled, colored contours) of the normalized summary statistics calculated by MODE, based on $C$. The magnitudes of cold pool lengths and surface areas were normalized for equal comparison by identifying the highest value of a given statistic among all 14 cases in 3-, 1-, and 0.333-km simulations, and scaling all values by dividing by the highest value.

were more similar to observations, particularly for the 1-km MCSs above the upper quartile range.

A bootstrap significance test was applied in the present study between observations and simulations, as well as between 3- and 1-km simulations themselves. Simulated MCSs were not significantly slower than observed MCSs for any given hour, except for t8 (Table 6), when most simulated MCSs began to dissipate while observed MCSs remained healthy. Similarly, while 1-km MCSs tended to accelerate and move faster than those at $3 \mathrm{~km}$, these hourly speedups were not statistically significant, though $p$ values at $\mathrm{t} 4$ and $\mathrm{t} 5$ were around 0.06-0.07 (Table 6), suggesting 1-km MCSs were noticeably faster than $3 \mathrm{~km}$ within this timeframe. However, when averaging observed and simulated MCS motions for $\mathrm{t} 1-\mathrm{t} 8$, for each case (not shown), 1-km 8-h time-averaged propagation speeds were significantly faster than those in $3-\mathrm{km}$ runs ( $p$ value of 0.007 ). No significant differences in these speeds were present comparing observations to $1 \mathrm{~km}$ ( $p$ value of 0.581 ) or observations to $3 \mathrm{~km}$ ( $p$ value of 0.364$)$.

It may be concluded that 3-km MCS speeds are slightly more representative of observations when comparing the averages only, but great case-to-case variability precludes a more definitive answer as to whether finer grid spacing results in a better forecast of MCS speeds. As cold pool expanse and intensity may serve as an impetus for MCS forward propagation speed, it becomes difficult to infer (in absence of a dense network of in situ observations) if decreasing $\Delta x$ from $3 \mathrm{~km}$ would result in a simulated cold pool more representative of reality throughout an observed MCSs evolution.

Though 1-km simulated MCSs moved faster overall compared to $3 \mathrm{~km}, 3-\mathrm{km}$ MCS forward propagation speeds more closely matched observed MCS speeds, differing from Schwartz et al. (2017), suggesting that in the present sample of cases, the faster speeds in $1-\mathrm{km}$ runs did not equate to a better forecast. The independent evaluation of observed and simulated MCS forward propagation speeds, however, did not take into account spatial or temporal MCS displacements. These forecast displacements must be accounted for to determine if finer grid-spaced solutions improve MCS forecast placement or QPF skill, potentially

TABLE 5. As in Table 4, but for MODE comparison statistics. Bootstrap resampling was applied to object comparisons between 0.333 and $3-\mathrm{km}$, and $0.333-$ and $1-\mathrm{km}$ cold pools.

\begin{tabular}{ll}
\hline Comparison variable & ASL \\
\hline Centroid distance & $\mathbf{0 . 0 1 7}$ \\
Angle difference & $\mathbf{0 . 0 0 7}$ \\
Symmetric difference & $\mathbf{0 . 0 0 9}$ \\
Area ratio & $\mathbf{0 . 0 2 6}$ \\
Intersection area & $\mathbf{0 . 0 0 2}$ \\
Intersection over area & $\mathbf{0 . 0 2 3}$ \\
\hline
\end{tabular}




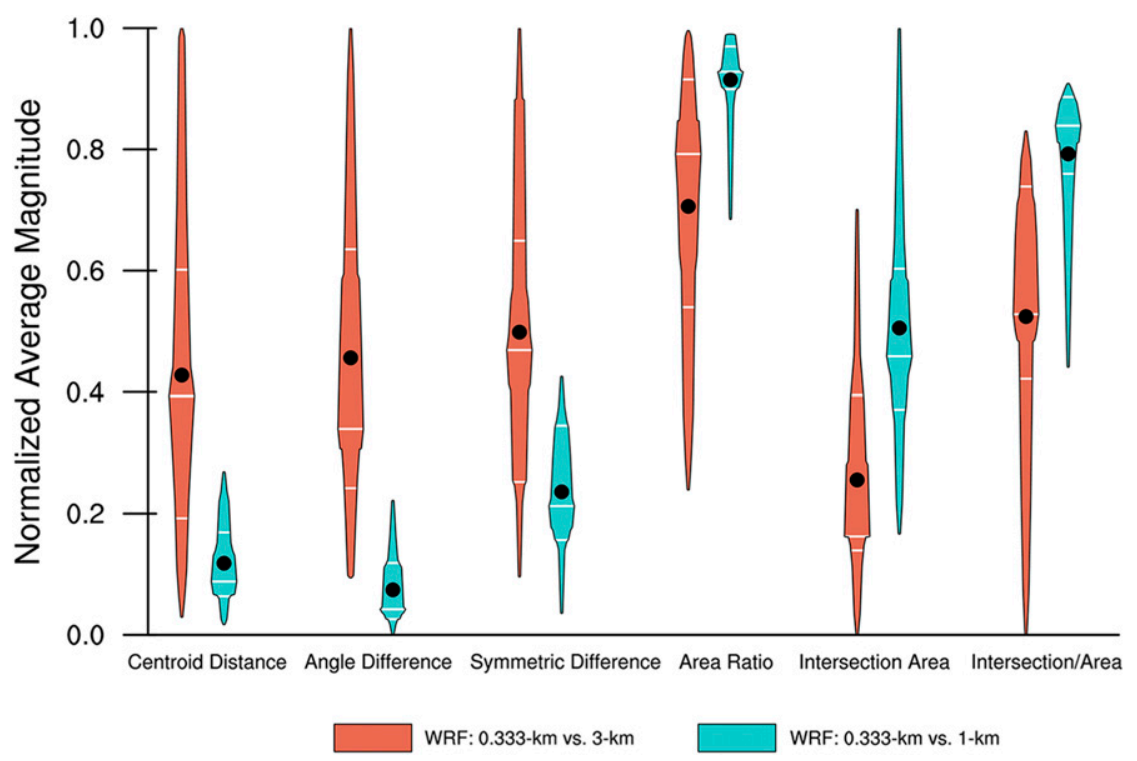

FIG. 10. Normalized comparison statistics of cold pools defined using $C$ in MODE (as in Fig. 9). The difference and ratio statistics were calculated by treating $0.333-\mathrm{km}$ runs as "control runs" when compared to 3 - and 1-km output. The magnitudes of centroid, angle, and symmetric differences, area ratios, intersection areas, and intersection over total area ratios were normalized for equal comparison by identifying the highest value of a given statistic among all 14 cases in 3-, 1-, and $0.333-\mathrm{km}$ simulations, and scaling all values by dividing by the highest value.

justifying the increased computational resources needed to run models at $1-\mathrm{km}$ grid spacing. Thus, an analysis of MCS QPF skill at fine spatial and temporal scales follows.

\section{c. Horizontal grid spacing impacts of MCS QPF forecast skill}

Precipitation swaths in the present study were evaluated over relatively small accumulation periods [i.e., 3-h accumulations, hourly, as opposed to 24-h accumulations in Schwartz et al. (2017)] so that QPF skill could be evaluated at finer temporal resolution. The goal was to determine if there were periods in simulated MCS life cycles where finer grid spacing would significantly improve QPF skill. MCS QPFs were also evaluated based on the convective initiation ("pre-MCS stage") and MCS upscale growth ("MCS stage") stages to determine if decreased $\Delta x$ improved QPFs for individual stages of MCS evolution. The period of convective initiation was defined as the period from when the first convective cells (that would eventually comprise the observed MCS) initiate, to MCS initiation time (at t0, when MCS structures were first observed, as described in section 2a). Observed precipitation was accumulated between convective initiation and t0 MCS initiation. For the "MCS stage", observed precipitation was accumulated for the 9-h periods for which the observed MCS forward propagation speeds were calculated.
The times evaluated in simulations were the same for the pre-MCS and MCS periods as in observations for direct comparison. A comparison of QPFSs for the developing, mature, weakening, and dissipation stages of MCSs, as done in Coniglio et al. (2010), was not possible in the present study because multiple observed and simulated MCSs moved out of the smaller $1000 \mathrm{~km} \times 1000 \mathrm{~km}$ domains before weakening or dissipating.

QPF skill for the pre-MCS stage was overall lower than for QPF skill during the MCS stage, for all radii of influence, for all tested precipitation thresholds, for both 3- and 1-km runs (Fig. 13). While 3- and 1-km QPFs were similarly skillful for the MCS stages, 1-km nETSs for a few cases (above the upper quartile range for the 6.4-, $12.7-$, and 25.4-mm thresholds, at all radii of influence) showed somewhat better skill than 3-km nETSs during the pre-MCS stages. For MCS QPF skill during the MCS stage (Fig. 14), for smaller radii of influence at all tested precipitation thresholds, the $1-\mathrm{km}$ case averaged and upper quartile nETSs were higher than those for $3 \mathrm{~km}$, particularly for the later hours (i.e., t5-t8) of MCS evolution. The 1- and 3-km nETSs became more similar for higher radii of influence.

The 1-km nETSs were not significantly more skillful than $3 \mathrm{~km}$ when comparing QPFs in the pre-MCS or MCS stages, as well as hourly 3-h accumulation derived nETSs in the MCS stage itself, regardless of the radii of 

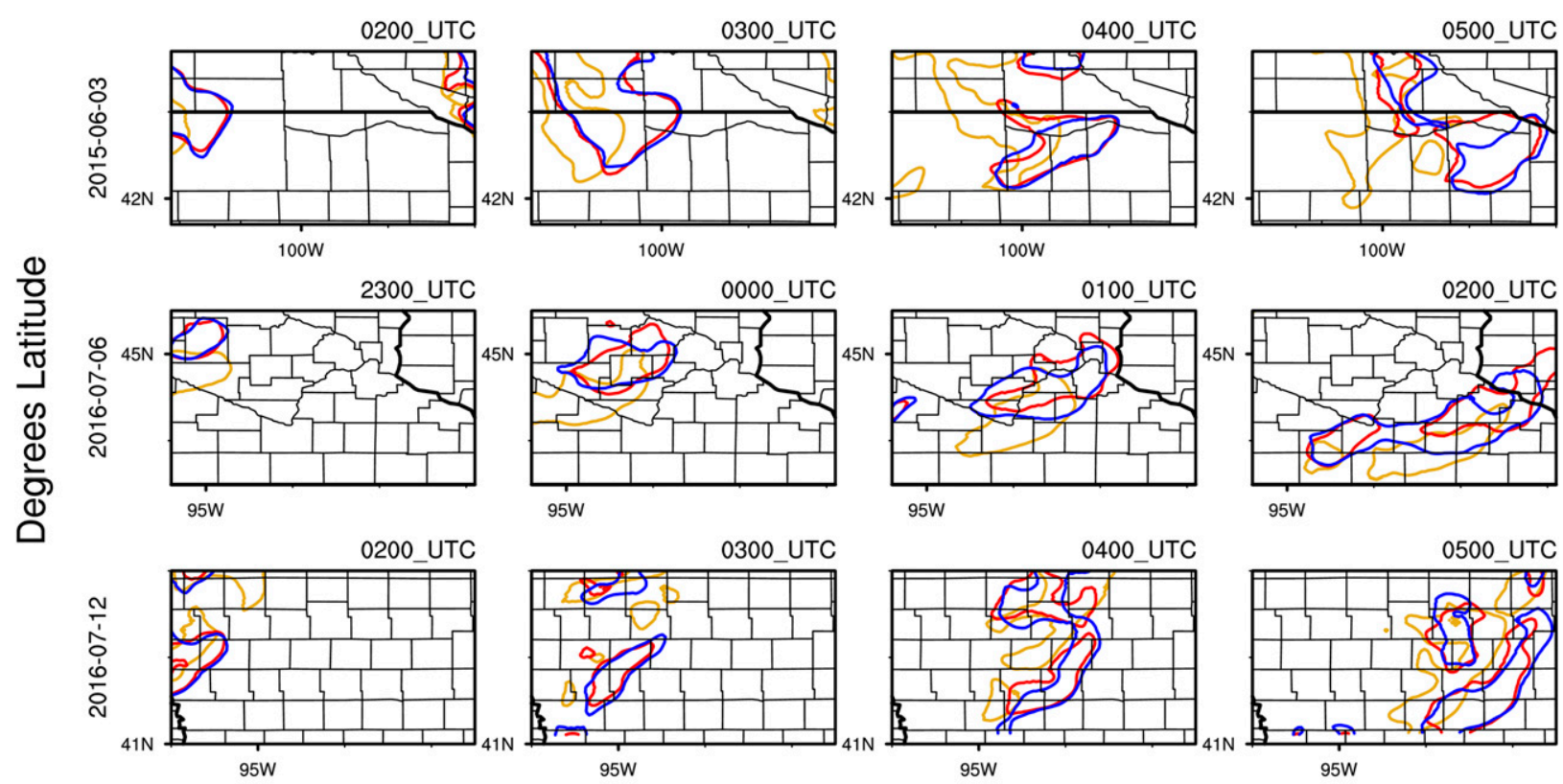

Degrees Longitude

3-km WRF

1-km WRF

$0.333-\mathrm{km}$ WRF

FIG. 11. Evolution of the developing to mature stages of four simulated MCS cold pools, starting with early stages within 1-3 h of MCS initiation (at left). Lined contours depict the upper quartile magnitudes of $C$ values, with gold, red, and blue overlays depicting 3-, 1-, and 0.333-km WRF simulations, respectively.

influence or precipitation threshold employed, prompting the question of whether decreasing $\Delta x$ from 3 to $1 \mathrm{~km}$ truly improves MCS QPFs. When MCS QPF swaths were accumulated across the 9 evaluated hours, for all cases composited, an overall improvement in QPF spatial and temporal placement in 1 - versus $3-\mathrm{km}$ simulations was noted (Fig. 15). Higher accumulation values $(4.0+\mathrm{mm})$ in $1-\mathrm{km}$ simulations were more aligned with observations compared to $3 \mathrm{~km}$, especially after $\mathrm{t} 4$ (in the 120-160 grid-square range, or approximately $600 \mathrm{~km}$ east of the western boundary of all domains), attesting to better placement of MCSs in $1-\mathrm{km}$ runs. The better alignment of the 1- versus 3-km composited QPF trends is especially evident when compared to observations via the $4.0 \mathrm{~mm}$ threshold (purple lined contour) in Fig. 15, particularly for hours $\mathrm{t} 5-\mathrm{t} 8$, roughly matching the better nETSs in 1- versus 3-km simulations noted in Fig. 14. This signal in QPF trends argues for some MCS QPF skill improvement as $\Delta x$ becomes smaller than $3 \mathrm{~km}$. Evaluating the 14 cases individually (exemplified with 6 cases; Fig. 16), the majority of the MCS precipitation (i.e., the $10-\mathrm{mm}$ threshold) was not as expansive in area in 3-km simulations as in 1-km runs or observations, with the observed and $1-\mathrm{km}$ simulated $10+\mathrm{mm}$ areal coverage of precipitation being significantly larger than that at $3 \mathrm{~km}$ (Table 7). For the 50-mm threshold, though, the areal coverage of observed precipitation, as well as 3- and 1-km QPFs, were more similar, with no statistically significant differences noted between observations and simulations. The areal overlap between observed precipitation and 1-km QPF, however, was significantly greater than the overlapping areas of

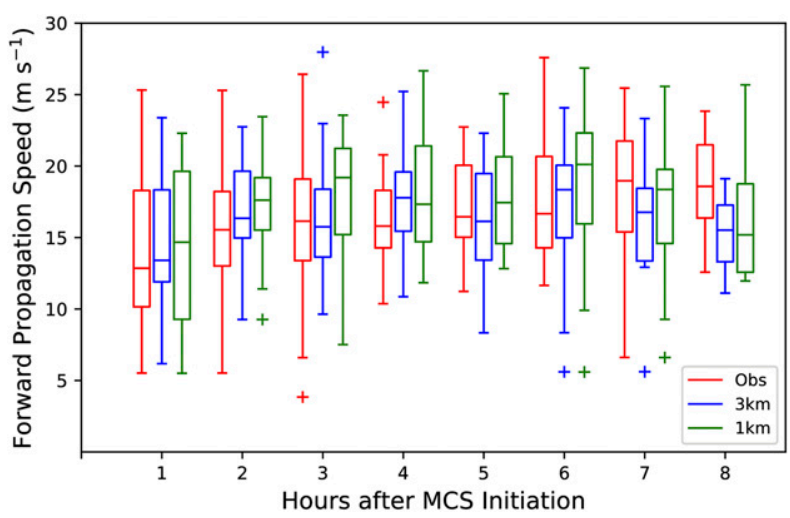

FIG. 12. Boxplot showing the spread of hourly averaged forward MCS propagation speed magnitudes for observations (red), 3-km (blue) and 1-km (green) WRF simulations, for the second through ninth hours of MCS evolution. The median is shown by bars within boxes, containing values within the lower and upper quartiles. Bars terminating with dashed lines cap the range of values within the distribution, except for outliers, depicted as + signs. 
TABLE 6. Bootstrap resampling-derived achieved level of significance ( $p$ values) for differences between observed and 3-km simulated, observed and 1-km simulated, and 3- and 1-km simulated averaged hourly MCS forward propagation speeds for $8 \mathrm{~h}$ after MCS initiation. Boldfaced ASL values (below 0.05) are considered statistically significant.

\begin{tabular}{cccc}
\hline \hline ASL & Obs vs 3 km & Obs vs 1 km & 3 vs 1 km \\
\hline t1 & 0.954 & 0.961 & 0.850 \\
t2 & 0.391 & 0.281 & 0.584 \\
t3 & 0.553 & 0.272 & 0.355 \\
t4 & 0.441 & 0.337 & 0.591 \\
t5 & 0.403 & 0.451 & 0.069 \\
t6 & 0.487 & 0.730 & 0.064 \\
t7 & 0.110 & 0.380 & 0.370 \\
t8 & $\mathbf{0 . 0 0 4}$ & $\mathbf{0 . 0 4 8}$ & 0.319 \\
\hline
\end{tabular}

observed precipitation and 3-km QPF, even for the 50 -mm threshold (Table 7), suggesting that increases in areal overlap between observed precipitation and finer $\Delta x$ runs contributed to improved QPF forecast skill.

\section{Discussion}

Concurring with Kain et al. (2008) and Schwartz et al. (2009), it is unclear whether decreasing $\Delta x$ from 3 to $1 \mathrm{~km}$ would provide any value to forecasts of larger-scale convective complexes and other phenomena similar in size. The 3- and 1-km explicitly calculated simulated forward propagation speeds in the last hour (t8) of analyzed MCS evolution were significantly slower than observed speeds, suggesting that models weakened MCSs too soon, regardless of $\Delta x$ chosen. On the other hand, there was significantly more overlap in 1-km QPF and observed QPE areas as opposed to 3-km and observed, suggesting that the larger precipitation swaths due to larger MCSs (and associated cold pools) does improve MCS QPF forecasts performed with finer $\Delta x$. However, this improvement may not be worth the computational costs of implementing 1-km or finer grid spacing, given that 1-km QPFs (3-h swaths, evaluated at hourly intervals, or in 9-h accumulated swaths) were not

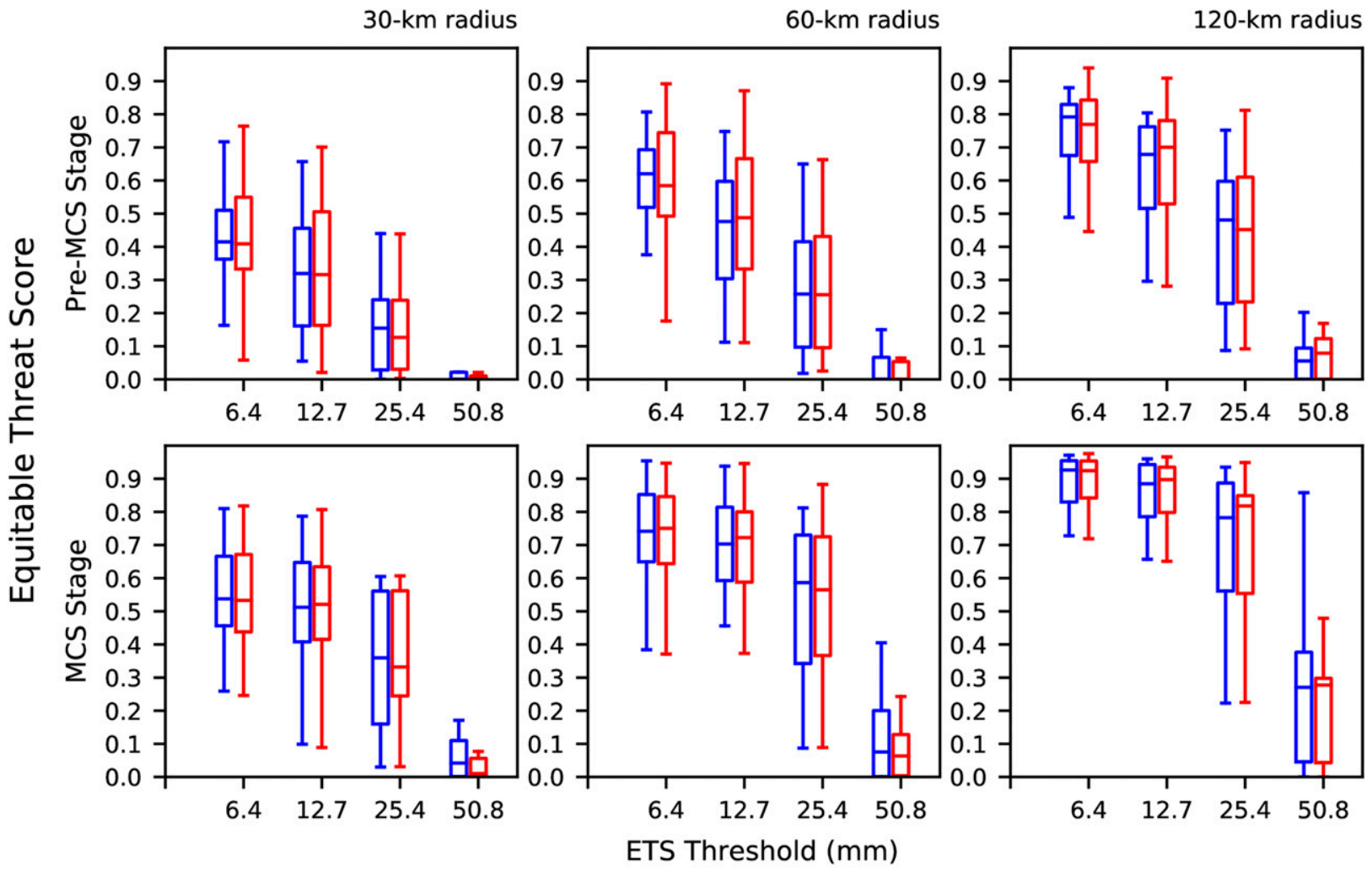

\section{$3 \mathrm{~km} \square 1 \mathrm{~km}$}

FIG. 13. Boxplots of neighborhood ETSs for 3- (blue) and 1-km (red) simulations for the (top) "pre-MCS" and (bottom) "MCS" stages of MCS evolution, employing (left) 30-, (center) 60-, and (right) 120-km radii of influence, at 6.35-, 12.70-, and 25.40-mm precipitation thresholds. The median is shown by bars within boxes, containing values within the lower and upper quartiles. Bars terminating with dashed lines cap the range of values within the distribution. 

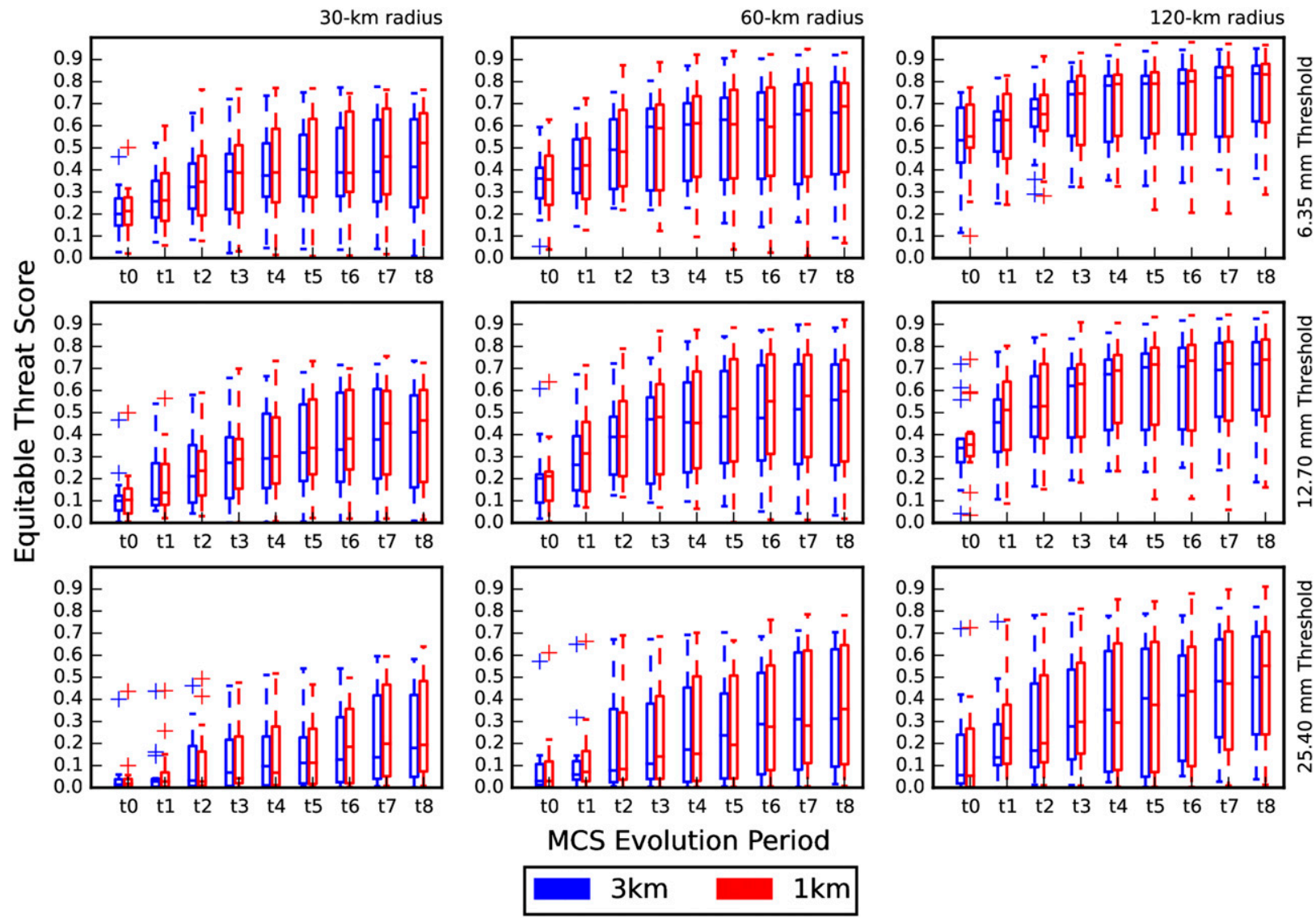

FIG. 14. As in Fig. 13, but for neighborhood ETSs (for 3-h QPFs) for 3- (blue) and 1-km (red) simulations for all 9-h of MCS evolution, employing (left) 30-, (center) 60-, and (right) 120-km radii of influence, at (top) 6.35-, (middle) 12.70-, and (bottom) 25.40-mm precipitation thresholds.

significantly more skillful than those at $3 \mathrm{~km}$. It was clearer, however, that decreasing $\Delta x$ finer than $1 \mathrm{~km}$ would not benefit MCS forecasts, as statistical properties of MCS cold pools in $0.333-\mathrm{km}$ simulations were significantly more similar to $1-\mathrm{km}$ runs than $3-\mathrm{km}$ events.

The present study also revealed some convective behaviors in need of more research. While 1 - and $0.333-\mathrm{km}$ MCS cold pools were more expansive than those in 3-km runs overall, there were occasions (in several cases), where 3-km events experienced a "burst" in intensity, such that 3-km cold pools were stronger than their finer counterparts (as exemplified in Fig. 4; left column). Previous literature had noted similar behavior in grid-spacing sensitivity studies of convection (i.e., precipitation rates in Bryan and Morrison 2012) and conjectured that inadequate resolving of vertical convective processes, such as midlevel entrainment, may be the cause for this behavior. With turbulent and convective eddy evolution and entrainment being $3 \mathrm{D}$ processes, it is important to explore sensitivities that vertical grid spacing $\Delta z$ has on simulated convective evolution. For more adequate representations of convection, $\Delta z$ may need to be decreased in tandem with $\Delta x$ rather than separately, as recommended by Schwartz et al. (2017).

In addition, more analysis must be performed to explain why MCS cold pools were significantly more expansive in the finer versus coarser $\Delta x$ runs in the first place. As shown by Bryan et al. (2003), Bryan and Morrison (2012), Lebo and Morrison (2015), and Verrelle et al. (2015) in idealized experiments, finer $\Delta x$ runs demonstrated narrower, but stronger and more numerous updrafts embedded within linear features, leading to a greater influx of hydrometeors, greater rainfall rates and thus, stronger evaporative cooling to produce more intense cold pools. For the real cases in the present study, a similar preliminary microphysical analysis was performed to explain cold pool evolution with changing $\Delta x$, but results varied greatly among cases, likely due to the heterogeneities in both ICs/LBCs and complexities introduced by model physics that would vary widely for each real-case-based 

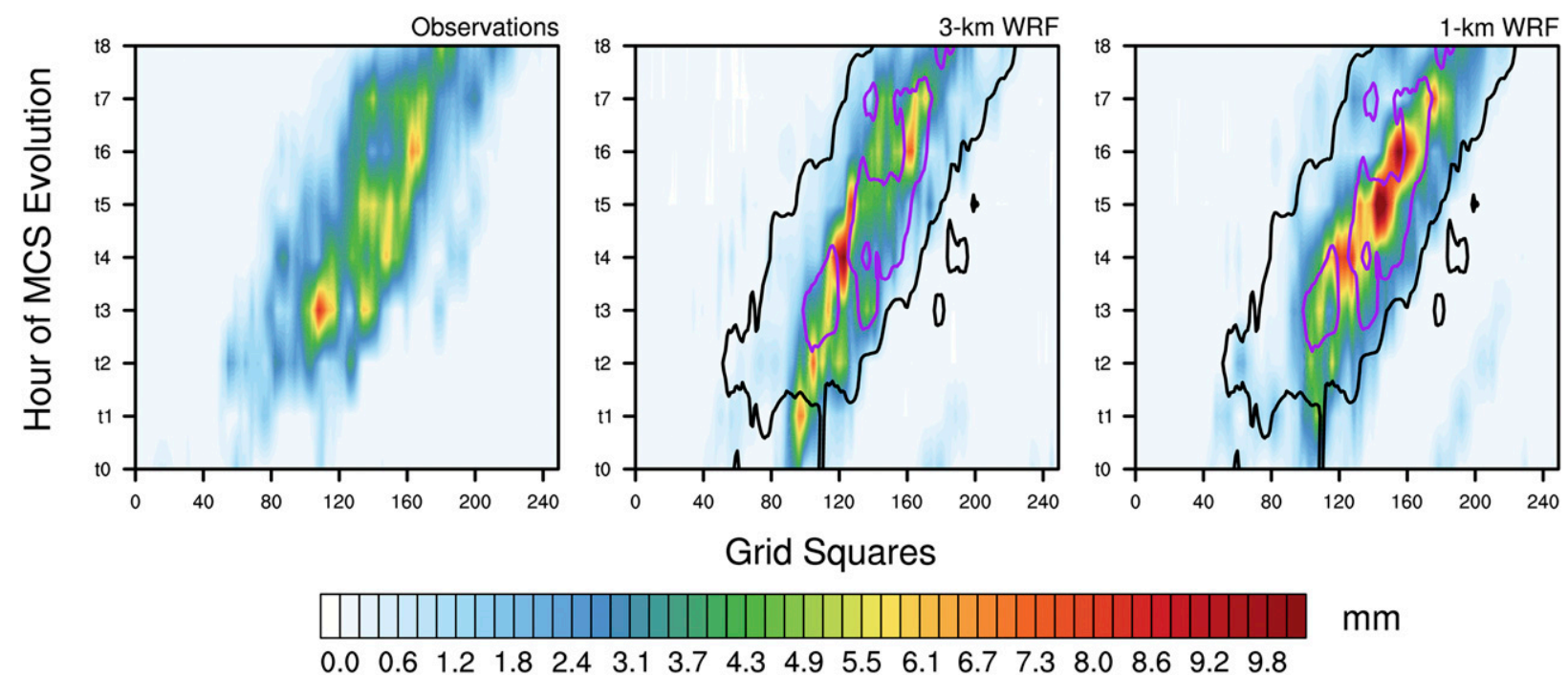

$\mathrm{mm}$

FIG. 15. Hovmöller diagram of MCS precipitation, from the time of MCS initiation, to $9 \mathrm{~h}$ out, for all $14 \mathrm{cases,}$ for (left) observations/Stage-IV, (center) 3-km, and (right) 1-km simulations. Observed precipitation values were overlaid upon 3- and 1-km diagrams at the 1.0- (black lined contours) and 4.0-mm (purple lined contours) thresholds. All data were composited over domains $(250 \times$ 250 grid squares or $1000 \mathrm{~km} \times 1000 \mathrm{~km}$ in area) having 4-km grid spacing, with the domain-centered latitude chosen to bisect the longitudes of the domain for optimized sampling of all precipitation swaths.

simulation. Several cases showed heavier rain rates along with stronger evaporative cooling with the finer $\Delta x$ simulations, likely inducing more expansive cold pools in 1- and $0.333-\mathrm{km}$ runs [as in Bryan and Morrison (2012) and Verrelle et al. (2015)], while other cases showed higher rain rates and stronger evaporative cooling in association with the aforementioned "bursts" in intensity with 3-km events. A simplified approach to exploring MCS cold pools for varying cases would be to composite ICs/LBCs from multiple events and run idealized CAMs, as in Peters and Schumacher (2016), to perform MCS evolution analyses for a single quasi-idealized event. This is likely to be the approach taken in future work to perform the aforementioned $\Delta x / \Delta z$ tasks to both simplify analyses and conserve computational resources.

The authors attempted to use the $2.5-\mathrm{km}$ gridded NOAA-NCEP Unrestricted Mesoscale Analysis (URMA) data, augmented with surface observations, to evaluate observed surface cold pools, but given the sparse nature of surface observations, despite interpolation, URMA often missed several cold pools. As such, it was not possible to sufficiently evaluate surface cold pools in this study. However, other studies such as Adams-Selin et al. (2013) were able to successfully depict observed cold pools using data from the Oklahoma Mesonet. Resimulating MCSs with varying grid spacing, which traversed the Oklahoma Mesonet (or other similar dense observational networks) would be ideal for determining which grid spacing most accurately depicts reality, as an adequate set of observations should be available for answering this question.

The 1-km Hovmöller composite showed noticeably higher accumulations compared to observations. As noted in Weisman et al. (2008), Bryan and Morrison (2012), and Adams-Selin et al. (2013), sensitivity to microphysics (MP) schemes exists in simulations of deep moist convection in CAMS, though Weisman et al. (2008) suggested that changes in MP schemes should not heavily impact operational guidance. The Thompson two-moment (2-M) MP scheme (Thompson et al. 2008) was employed in the present study, and it was noted by Morrison et al. (2009) that 2-M MP schemes tend to overproduce stratiform rain, with a weaker distinction between convective and immediately postconvective stratiform rain regions, likely contributing to a well-known (Weisman et al. 2008) wet bias in WRF. While MP sensitivity tests were beyond the scope of this study, the sensitivity to MP scheme of grid spacing impacts on QPF and simulated cold pool characteristics should be investigated in future work.

The real value in decreasing $\Delta x$ to finer than $3 \mathrm{~km}$ may be in evaluating storm-scale behavior and the potential for severe convective events. In Flournoy and Coniglio (2019), 1-km ensemble WRF simulations were able to resolve strong storm-scale low-level circulations embedded within an MCS, which spawned a tornado in reality. In the present study, a line-embedded circulation, with a relatively longer-lived surface vertical vorticity signal (resolved at $1 \mathrm{~km}$ ) similar to that of 

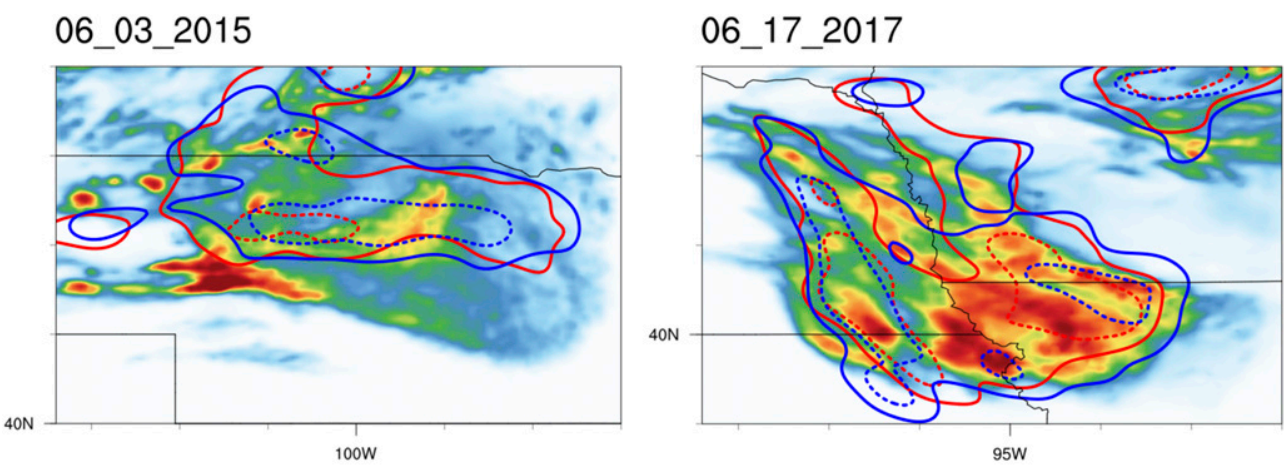

\section{6_18_2015}

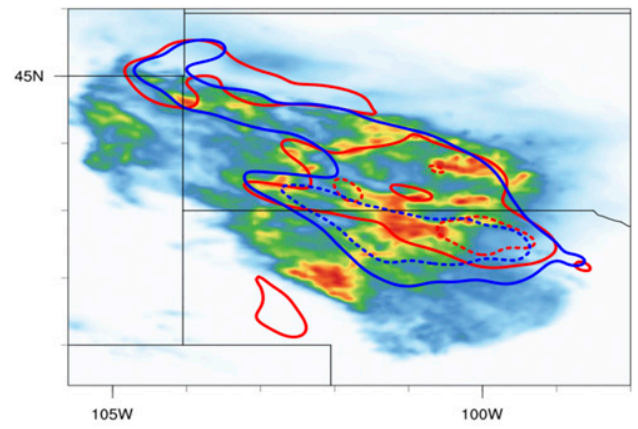

07_13_2015

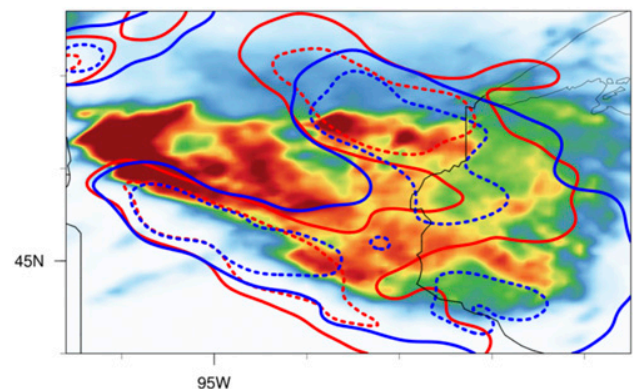

07_06_2016

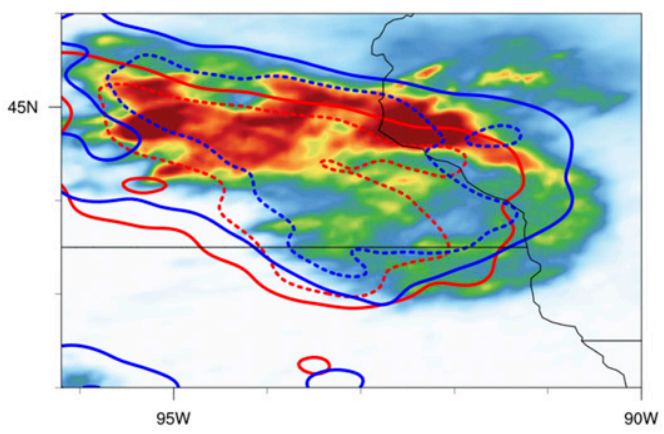

07_18_2015

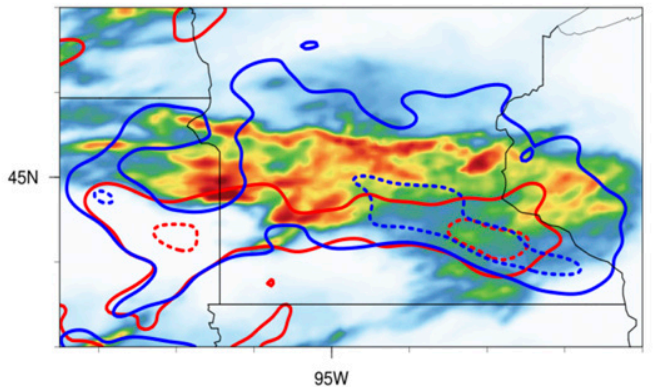

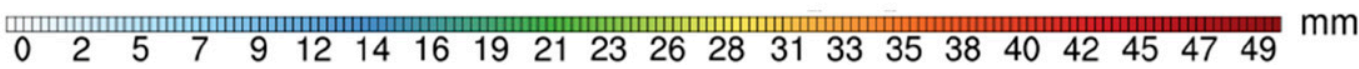

FIG. 16. The 9-h accumulated precipitation swaths for six selected cases. Filled contours denote observed precipitation $(\mathrm{mm})$, with red solid and dashed line contours depicting 10 and $25 \mathrm{~mm}$, respectively, accumulated precipitation for 3-km WRF, and blue solid and dashed lines for 10 and $25 \mathrm{~mm}$, respectively, accumulated 1-km WRF precipitation.

Flournoy and Coniglio (2019) was also observed, in one case, but the circulation was a false alarm. Still, the greatest value in refining grid spacing may be to ascertain storm threats such as tornadoes, and downbursts, which would be invaluable for short-term severe storms forecasting, a key goal of the developing Warn-on Forecast program within the National Severe Storms Laboratory (Stensrud et al. 2013).

\section{Summary and conclusions}

Simulated mature MCS cold pools were significantly more expansive (evident via $C$ ) in WRF runs using 1 - and $0.333-\mathrm{km}$ horizontal grid spacing than in runs using $3 \mathrm{~km}$. Significant differences were present in simulated MCS cold pools when decreasing $\Delta x$ from 3 to $1 \mathrm{~km}$, but model solutions became more similar when $\Delta x$ was decreased from 1 to $0.333 \mathrm{~km}$. In addition, there was significantly more agreement between the finer $\Delta x$ runs regarding placement and areal overlapping of cold pools. The greater similarity in solutions between 1 and $0.333 \mathrm{~km}$ suggested little operational value is added to implementing $\Delta x$ below $1 \mathrm{~km}$ for larger-scale convective complexes, as also suggested by Verrelle et al. (2015).

MCSs in 1-km runs moved significantly faster than in 3-km runs throughout the life of an MCS, with 3-km speeds matching observed speeds more closely. MCS QPF skill 
TABLE 7. Bootstrap resampling-derived achieved level of significance ( $p$ values) for differences between observed and 3-km, observed and 1-km, and 3- and 1-km simulated 9-h accumulated precipitation areas for the $10-\mathrm{mm}$ (middle column) and $50-\mathrm{mm}$ (right column) thresholds. Boldfaced ASL values (below 0.05) are considered statistically significant.

\begin{tabular}{lcc}
\hline \multicolumn{1}{c}{ ASL } & $10 \mathrm{~mm}$ & $50 \mathrm{~mm}$ \\
\hline Obs vs 3-km area & $\mathbf{0 . 0 0 7}$ & 0.766 \\
Obs vs 1-km area & 0.127 & 0.826 \\
3- vs 1-km area & $\mathbf{0 . 0 0 1}$ & 0.078 \\
Obs/3-km vs obs/1-km overlap & $\mathbf{0 . 0 0 1}$ & $\mathbf{0 . 0 0 0}$ \\
\hline
\end{tabular}

exhibited overall higher nETSs in 1-km runs compared to $3 \mathrm{~km}$, though the differences were not statistically significant. Despite the forecast improvements associated with 1-km simulations shown in this work, CAMs still struggled in accurately simulating the initiating and early stages of MCS evolution, and more work needs to be done to better understand model failures in accurately organizing an MCS.

Acknowledgments. This research was sponsored by the National Science Foundation (NSF) under Grant AGS-1624947. Additional acknowledgement is provided to the NSF and National Centers for Environmental Prediction (NCEP) for allowing the first author to partake in the NSF/NCEP visiting scientist program through an NSF supplement to AGS-1222383, where preliminary work and feedback from NOAA employees at the Storm Prediction Center (SPC), Environmental Modeling Center (EMC) and National Severe Storms Laboratory (NSSL) provided a framework for the current research. Acknowledgement is given to the high-performance computing support from Cheyenne (doi:10.5065/D6RX99HX) provided by NCAR's Computational and Information Systems Laboratory, sponsored by the National Science Foundation. Stage-IV data were provided by NCAR/EOL under sponsorship of the National Science Foundation (http://data.eol.ucar.edu/). Gratitude is extended to Dr. Adam Clark (NSSL) for supplying code to calculate neighborhood-based equitable threat scores. The authors are also grateful for assistance provided by Dr. Burkely T. Gallo (CIMMS), Julie Prestopnik, and John Halley Gotway (UCAR) to configure the MODE software for the evaluation of MCS cold pools. The paper benefitted as well from the constructive comments made by the editor and three anonymous reviewers.

\section{REFERENCES}

Abatan, A. A., and Coauthors, 2018: Statistics of multi-year droughts from the method for object-based diagnostic evaluation. Int. J. Climatol., 38, 3405-3420, https://doi.org/10.1002/joc.5512.

Adams-Selin, R. D., S. C. Van Den Heever, and R. H. Johnson, 2013: Sensitivity of bow-echo simulation to microphysical parameterizations. Wea. Forecasting, 28, 1188-1209, https:// doi.org/10.1175/WAF-D-12-00108.1.

Anagnostou, E. N., 2004: A convective/stratiform precipitation classification algorithm for volume scanning weather radar observations. Meteor. Appl., 11, 291-300, https://doi.org/ 10.1017/S1350482704001409.

Benjamin, T. B., 1968: Gravity currents and related phenomena. J. Fluid Mech., 31, 209-248, https://doi.org/10.1017/ S0022112068000133.

Bryan, G. H., and H. Morrison, 2012: Sensitivity of a simulated squall line to horizontal resolution and parameterization of microphysics. Mon. Wea. Rev., 140, 202-225, https://doi.org/ 10.1175/MWR-D-11-00046.1.

_ J. C. Wyngaard, and J. M. Fritsch, 2003: Resolution requirements for the simulation of deep moist convection. Mon. Wea. Rev., 131, 2394-2416, https://doi.org/10.1175/1520-0493(2003) $131<2394$ :RRFTSO $>2.0$. CO; .

Bullock, R. G., B. G. Brown, and T. L. Fowler, 2016: Method for object-based diagnostic evaluation. NCAR Tech. Note NCAR/ TN-532+STR, 84 pp., https://doi.org/doi:10.5065/D61V5CBS.

Clark, A. J., W. A. Gallus Jr., M. Xue, and F. Kong, 2009: A comparison of precipitation forecast skill between small nearconvection-permitting and large convection-parameterizing ensembles. Wea. Forecasting, 24, 1121-1140, https://doi.org/ 10.1175/2009WAF2222222.1.

_ _ _ , and M. L. Weisman, 2010: Neighborhood-based verification of precipitation forecasts from convection-allowing NCAR WRF Model simulations and the operational NAM. Wea. Forecasting, 25, 1495-1509, https://doi.org/10.1175/2010WAF2222404.1.

Computational and Information Systems Laboratory, 2017: Cheyenne: HPE/SGI ICE XA System (University Community Computing). National Center for Atmospheric Research, accessed 1 January 2017, https://doi.org/10.5065/D6RX99HX.

Coniglio, M. C., J. Y. Hwang, and D. J. Stensrud, 2010: Environmental factors in the upscale growth and longevity of MCSs derived from Rapid Update Cycle analyses. Mon. Wea. Rev., 138, 3514-3539, https://doi.org/10.1175/2010MWR3233.1.

Davis, C. A., B. G. Brown, and R. G. Bullock, 2006a: Object-based verification of precipitation forecasts. Part I: Methods and application to mesoscale rain areas. Mon. Wea. Rev., 134, 1772-1784, https://doi.org/10.1175/MWR3145.1.

$\_,-$, and - , 2006b: Object-based verification of precipitation forecasts. Part II: Application to convective rain systems. Mon. Wea. Rev., 134, 1785-1795, https://doi.org/10.1175/MWR3146.1.

- __ _ R. Bullock, and J. Halley-Gotway, 2009: The Method for Object-based Diagnostic Evaluation (MODE) applied to numerical forecasts from the 2005 NSSL/SPC Spring Program. Wea. Forecasting, 24, 1252-1267, https://doi.org/ 10.1175/2009WAF2222241.1.

Done, J., C. A. Davis, and M. L. Weisman, 2004: The next generation of NWP: Explicit forecasts of convection using the Weather Research and Forecasting (WRF) model. Atmos. Sci. Lett., 5, 110-117, https://doi.org/10.1002/asl.72.

Flournoy, M. D., and M. C. Coniglio, 2019: Origins of vorticity in a simulated tornadic mesovortex observed during PECAN on 6 July 2015. Mon. Wea. Rev., 147, 107-134, https://doi.org/ 10.1175/MWR-D-18-0221.1.

French, A. J., and M. D. Parker, 2010: The response of simulated nocturnal convective systems to a developing low-level jet. J. Atmos. Sci., 67, 3384-3408, https://doi.org/10.1175/2010JAS3329.1.

Gallus, W. A., Jr., 2010: Application of object-based verification techniques to ensemble precipitation forecasts. Wea. Forecasting, 25, 144-158, https://doi.org/10.1175/2009WAF2222274.1. 
, and M. Pfeifer, 2008: Intercomparison of simulations using 5 WRF microphysical schemes with dual-polarization data for a German squall line. Adv. Geosci., 16, 109-116, https://doi.org/ 10.5194/adgeo-16-109-2008.

Iowa State University, 2018: Iowa Environmental Mesonet. Department of Agronomy, Iowa State University, https:// mesonet.agron.iastate.edu/docs/nexrad_composites/.

James, R., J. Fritsch, and P. Markowski, 2005: Environmental distinctions between cellular and slabular convective lines. Mon. Wea. Rev., 133, 2669-2691, https://doi.org/10.1175/MWR3002.1.

Johnson, A., X. Wang, F. Kong, and M. Xue, 2013: Object-based evaluation of the impact of horizontal grid spacing on convection-allowing forecasts. Mon. Wea. Rev., 141, 34133425, https://doi.org/10.1175/MWR-D-13-00027.1.

Kain, J. S., and Coauthors, 2008: Some practical considerations regarding horizontal resolution in the first generation of operational convection-allowing NWP. Wea. Forecasting, 23, 931-952, https://doi.org/10.1175/WAF2007106.1.

Kong, F., K. K. Droegemeier, and N. L. Hickmon, 2006: Multiresolution ensemble forecasts of an observed tornadic thunderstorm system. Part I: Comparison of coarse- and finegrid experiments. Mon. Wea. Rev., 134, 807-833, https:// doi.org/10.1175/MWR3097.1.

Lebo, Z. J., and H. Morrison, 2015: Effects of horizontal and vertical grid spacing on mixing in simulated squall lines and implications for convective strength and structure. Mon. Wea. Rev., 143, 4355-4375, https://doi.org/10.1175/MWR-D-15-0154.1.

Mendenhall, W., and T. Sincich, 2007: Statistics for Engineering and the Sciences. 5th ed. Pearson-Prentice Hall, 1060 pp.

Morrison, H., G. Thompson, and V. Tatarskii, 2009: Impact of cloud microphysics on the development of trailing stratiform precipitation in a simulated squal line: Comparison of oneand two-moment schemes. Mon. Wea. Rev., 137, 991-1007, https://doi.org/10.1175/2008MWR2556.1.

NCAR/UCAR/EOL, 2015: GCIP/EOP surface: Precipitation NCEP/EMC 4KM Gridded Data (GRIB) stage IV data. Subset used: August 2013-June 2017, accessed 17 June 2018, http://data.eol.ucar.edu/cgi-bin/codiac/fgr_form/id=21.093.

NOAA/NCDC, 2015: NCEP numerical weather prediction models North American meso-scale grid 218. Subset used: May 2007-June 2014, accessed 23 February 2015, http://nomads.ncdc.noaa.gov/ cgi-bin/ncdc-ui/definecollection.pl?model_s ys=nam\&model_ name $=$ nam $\&$ grid_name $=218$.

Parker, M. D., and R. H. Johnson, 2000: Organizational modes of midlatitude mesoscale convective systems. Mon. Wea. Rev., 128, 3413-3436, https://doi.org/10.1175/1520-0493(2001)129<3413: OMOMMC $>2.0 . \mathrm{CO} ; 2$

Peters, J. M., and R. S. Schumacher, 2016: Dynamics governing a simulated mesoscale convective system with a training convective line. J. Atmos. Sci., 73, 2643-2664, https://doi.org/ 10.1175/JAS-D-15-0199.1.

Pinto, J. O., J. A. Grim, and M. Steiner, 2015: Assessment of the HighResolution Rapid Refresh Model's ability to predict mesoscale convective systems using object-based evaluation. Wea. Forecasting, 30, 892-913, https://doi.org/10.1175/WAF-D-14-00118.1.

Potvin, C. K., and M. L. Flora, 2015: Sensitivity of idealized supercell simulations to horizontal grid spacing: Implications for Warn-on-Forecast. Mon. Wea. Rev., 143, 2998-3024, https:// doi.org/10.1175/MWR-D-14-00416.1.

Przybylinski, R. W., 1995: The bow echo: Observations, numerical simulations, and severe weather detection methods. Wea. Forecasting, 10, 203-218, https://doi.org/10.1175/1520-0434(1995) $010<0203$ :TBEONS $>2.0$. CO;2.
Rosenfeld, D., D. B. Wolff, and E. Amitai, 1994: The window probability matching method for rainfall measurements with radar. J. Appl. Meteor., 33, 682-693, https://doi.org/10.1175/ 1520-0450(1994)033<0682:TWPMMF >2.0.CO;2.

Rotunno, R., J. B. Klemp, and M. L. Weisman, 1988: A theory for strong, long-lived squall lines. J. Atmos. Sci., 45, 463-485, https:// doi.org/10.1175/1520-0469(1988)045<0463:ATFSLL $>2.0 . C O ; 2$.

Schwartz, C. S., and Coauthors, 2009: Next-day convectionallowing WRF model guidance: A second look at 2-km versus 4-km grid spacing. Mon. Wea. Rev., 137, 3351-3372, https:// doi.org/10.1175/2009MWR2924.1.

, G. S. Romine, K. R. Fossell, R. A. Sobash, and M. L. Weisman, 2017: Toward 1-km ensemble forecasts over large domains. Mon. Wea. Rev., 145, 2943-2969, https://doi.org/ 10.1175/MWR-D-16-0410.1.

Skamarock, W. C., and Coauthors, 2008: A description of the Advanced Research WRF version 3. NCAR Tech. Note NCAR/TN-475+STR, 113 pp., http://.doi.org/10.5065/D68S4MVH.

Smith, T. M., and Coauthors, 2016: Multi-Radar Multi-Sensor (MRMS) severe weather and aviation products: Initial operating capabilities. Bull. Amer. Meteor. Soc., 97, 1617-1630, https://doi.org/10.1175/BAMS-D-14-00173.1.

Squitieri, B. J., and W. A. Gallus Jr., 2016: WRF forecasts of Great Plains nocturnal low-level jet driven MCSs. Part I: Correlation between low-level jet forecast accuracy and MCS precipitation forecast skill. Wea. Forecasting, 31, 1301-1323, https://doi.org/ 10.1175/WAF-D-15-0151.1.

Stensrud, D. J., and Coauthors, 2013: Progress and challenges with warn-on-forecast. Atmos. Res., 123, 2-16, https:// doi.org/10.1016/j.atmosres.2012.04.004.

Thompson, G., P. R. Field, W. D. Hall, and R. M. Rasmussen, 2008: Explicit forecasts of winter precipitation using an improved bulk microphysics scheme. Part II: Implementation of a new snow parameterization. Mon. Wea. Rev., 136, 5095-5115, https://doi.org/10.1175/2008MWR2387.1.

VandenBerg, M. A., M. C. Coniglio, and A. J. Clark, 2014: Comparison of next-day convection-allowing forecasts of storm motion on 1- and 4-km grids. Wea. Forecasting, 29, 878893, https://doi.org/10.1175/WAF-D-14-00011.1.

Verrelle, A., D. Ricard, and C. Lac, 2015: Sensitivity of high resolution idealized simulations of thunderstorms to horizontal resolution and turbulence parameterization. Quart. J. Roy. Meteor. Soc., 141, 433-448, https://doi.org/10.1002/ qj.2363.

Weisman, M. L., and R. Rotunno, 2004: "A theory for strong longlived squall lines" revisited. J. Atmos. Sci., 61, 361-382, https:// doi.org/10.1175/1520-0469(2004)061<0361:ATFSLS > 2.0.CO;2.

__ J. B. Klemp, and R. Rotunno, 1988: Structure and evolution of numerically simulated squall lines. J. Atmos. Sci., $\mathbf{4 5}$, 1990-2013, https://doi.org/10.1175/1520-0469(1988)045<1990 SAEONS $>2.0 . \mathrm{CO} ; 2$.

- W. C. Skamarock, and J. B. Klemp, 1997: The resolution dependence of explicitly modeled convective systems. Mon. Wea. Rev., 125, 527-548, https://doi.org/10.1175/1520-0493(1997) 125<0527:TRDOEM >2.0.CO;2.

, C. Davis, W. Wang, K. W. Manning, and J. B. Klemp, 2008: Experiences with 0-36-h explicit convective forecasts with the WRF-ARW model. Wea. Forecasting, 23, 407-437, https:// doi.org/10.1175/2007WAF2007005.1.

Wyngaard, J. C., 2004: Toward numerical modeling in the "terra incognita.' J. Atmos. Sci., 61, 1816-1826, https://doi.org/10.1175/ 1520-0469(2004)061<1816:TNMITT>2.0.CO;2. 